\title{
Sustainable Reconfigurable Manufacturing System Design Using Adapted Multi-Objective Evolutionary Based Approaches
}

Imen Khettabi

LaROMaD

Lyes Benyoucef ( $\square$ lyes.benyoucef@lis-lab.fr)

Aix-Marseille Universite

Mohamed Amine Boutiche

LaROMaD

\section{Research Article}

Keywords: Reconfigurable manufacturing system, sustainability, greenhouse gases, liquid hazardous wastes, multi-objective optimization, NSGA-III, hypervolume metric, spacing metric

Posted Date: March 12th, 2021

DOl: https://doi.org/10.21203/rs.3.rs-280732/v1

License: (c) (i) This work is licensed under a Creative Commons Attribution 4.0 International License. Read Full License 


\title{
Sustainable reconfigurable manufacturing system design using adapted multi-objective evolutionary based approaches
}

\author{
Imen Khettabi ${ }^{1}$. Lyes Benyoucef ${ }^{2}$. Mohamed Amine Boutiche ${ }^{1}$ \\ ${ }^{1}$ DGRSDT, LaROMaD Laboratory, Algiers \\ imen.khettabi1@gmail.com; mboutiche@gmail.com \\ ${ }^{2}$ Aix Marseille University, University of Touloun, CNRS, LIS, Marseille, France \\ lyes.benyoucef@lis-lab.fr
}

\begin{abstract}
Nowadays, manufacturing systems should be cost-effective and environmentally harmless to cope with various challenges in today's competitive markets. In this paper, we aim to solve an environmental oriented multiobjective reconfigurable manufacturing system design (ie., sustainable reconfigurable machines and tools selection) in the case of a single unit process plan generation. A non-linear multi-objective integer program (NL-MOIP) is presented first, where four objectives are minimised respectively, the total production cost, the total production time, the amount of the greenhouse gases emitted by machines and the hazardous liquid wastes. Second, to solve the problem, we propose four adapted versions of evolutionary approaches, namely two versions of the well known non-dominated sorting genetic algorithm (NSGA-II and NSGA-III), weighted genetic algorithms (WGA) and random weighted genetic algorithms (RWGA). To illustrate the efficiency of the four approaches, several instances of the problem are experimented and the obtained results are analysed using three metrics respectively hypervolume, spacing metric and cardinality of the mixed Pareto fronts. Moreover, the influences of the probabilities of genetic operators on the convergence of the adapted NSGAIII are analysed and TOPSIS method is used to help the decision maker ranking and selecting the best process plans.
\end{abstract}

Keywords: Reconfigurable manufacturing system, sustainability, greenhouse gases, liquid hazardous wastes, multi-objective optimization, NSGA-III, hypervolume metric, spacing metric.

\section{Introduction}

Nowadays, manufacturing enters a new context in which all manufacturers must compete in a global environment. As a result, global competition improves the selectivity of the customers, which drives the introduction of new products and causes large changes in products demands. Customer satisfaction is the main task for most companies. To stay competitive, manufacturers must use systems that not only produce in a high production rate, allowing rapid and cost-effective response to market changes, but also environmentally harmless. Therefore, manufacturers are moving towards a recent concept of production able to rapidly change in its structure (hardware and software items). 
Reconfigurable manufacturing system (RMS) is a novel paradigm designed at the outset for rapid change in structure, as well as in hardware and software components, in order to quickly adjust production capacity and functionality within a part family in response to sudden changes in market or in regulatory requirements (Koren et al. (1999)). According to Koren \& Shpitalni (2010) "RMS is designed to combine the high flexibility of flexible manufacturing system (FMS) with the high production rate of dedicated manufacturing system $(D M S)$ ". It is achieved by designing the system according to two principles ((Koren, 2010), (Koren, 2006)): i) design of a system and its machines for adjustable structure that enable system scalability in response to market demands and system/machine adaptability to new products. Structure may be adjusted at the system level (e.g., adding machines) and at the machine level (e.g., changing machine hardware and control software). This reduces the system time. ii) design of a system around the part family, with the customized flexibility required for producing all parts of this part family. This reduces the system cost.

More and more, companies are considering sustainability as an essential factor. Statistics have shown that the greenhouse gases (GHG) emitted from the use of energy sources such as electricity, coal, oil and gas during manufacturing accounts for over $37 \%$, even $50 \%$, of the total GHG worldwide. Therefore, companies have started to take measures to reduce GHG emissions from their products and services. Sustainable manufacturing is defined by the U.S. Department of Commerce as "creation of manufactured products using processes that minimize negative environmental impacts, conserve energy and natural resources, are safe for employees, communities and consumers" (Howard, 2014). More recently, RMS is thought to be one of the most suitable paradigms with the requirements of sustainability. Bi (2011) addressed how RMS can be connected to sustainable manufacturing from the point of view of sustainability production. Manufacturing processes and manufacturing activities are also classified as major sources of greenhouse gas (GHG) emissions.

In this paper, we address an environmental oriented multi-objective RMS design problem (ie., sustainable reconfigurable machines and tools selection). Firstly, a non-linear multi-objective integer program (NLMOIP) is presented in the case of a single unit process plan generation, where four objectives are minimised respectively, the total production cost, the total production time, the amount of the greenhouse gases emitted by machines and the hazardous liquid wastes. Furthermore, to solve the problem, adapted versions of the weighted genetic algorithm (WGA), random weighted genetic algorithm (RWGA) and the well-known non-dominated sorting genetic algorithm respectively (NSGA-II) and (NSGA-III) are presented. Finally, to illustrate the comparisons between the four approaches, rich experimental results are presented and analysed.

The rest of the paper is organised as follows: Section 2 reviews some research works dedicated to reconfigurable manufacturing problems including process plan generation and sustainability issues. Section 3 describes the problem under consideration and its mathematical formulation. Section 4 details the four adapted evolutionary approaches, namely, WGA, RWGA, NSGA-II and NSGA-III. Section 5 presents and analyses some experimental results. Finally, section 6 concludes the paper with some future work directions. 


\section{Literature Review}

Reconfigurable manufacturing system is one of the latest manufacturing paradigms. RMS offers new aspects and faces many new challenges. These possibilities make RMS a very active research field (Koren et al., 2018); (Maganha et al., 2018). Nevertheless, in this section, we briefly review some research works dedicated to RMS design problems, sustanability and manufacturing, and sustainability in RMS.

\subsection{Reconfigurable Manufacturing System Design}

According to Mehrabi et al. (2000), "RMS is a system where machines, machine components as well as the handling system can be added, modified, deleted or exchanged, integrated a new technologies according to production requirements in order to react faster to the constant evolution, unexpected demand for products and to the variety of products". Nourelfath et al. (2002) addressed the problem of designing an RMS able to work even if one of its components fails, with some performance degradation. ElMaraghy (2007) argued that: "changes and evolutions of manufacturing systems as well as products need to be related to reconfiguration and reconfigurable process planning". Goyal et al. (2012) defined the reconfigurability as: "the ability of a manufacturing system to easily and cost-effectively change and reorient its components frequently, in order to attain the objectives". The process planning (called also process plan generation) is defined by Swamidass (2000) as: "a preparatory step before manufacturing, which determines the sequence of operations or processes needed to produce a part or an assembly".

Spicer \& Carlo (2007) presented a combined integer programming/dynamic programming heuristic in order to determine an optimal configuration path of a scalable RMS by considering the cost and reconfiguration as performance measures. Musharavati \& Hamouda (2012) investigated the use of simulated annealing-based algorithms in solving process planning problem for a RMS. Chaube et al. (2012) and Bensmaine et al. (2013) integrated the cost and time-efficient problem of process plan generation using the adapted the non-dominated sorting genetic algorithm (NSGA-II). They elaborated rich experimental comparisons and analyses based on the obtained Pareto fronts. Hasan \& Jain (2015) introduced a method that can be modified for optimal selection of machine configurations across stages for a serial reconfigurable product flow line. Bensmaine et al. (2013) adapted a multi-objective based method for a reconfigurable manufacturing system design, which consists in selecting a subset of machines from a set of possible candidate machines to operate a set of operations needed to manufacture a given product. Haddou-Benderbal et al. (2016) discussed machines unavailability in RMS by developing a new hybrid heuristic to minimize the impact of perturbations caused by eventual unavailability of selected machines on the system. Wang et al. (2017) developed quantitative index models that reflect the essential characteristics of an RMS (scalability, convertibility, diagnosability, modularity, integrability, and customization) and rank alternative reconfiguration schemes, which possess both advantages and disadvantages. The authors used an integrated AHP method and two-phase PROMETHEE method to achieve a comprehensive evaluation of the alternatives. Recently, Haddou-Benderbal et al. (2018) developed an adapted version of the AMOSA based on modularity to solve the integrated design and process plan gen- 
eration problem for RMS. Moreover, Haddou-Benderbal \& Benyoucef (2019) considered the relations, which link the designed system with two important issues: its logical environment, i.e., the product family in which the RMS can evolve, and its physical environment, i.e., the physical workshop that implements the RMS. A two-phase based-AMOSA approach is developped to determine the best machine layout for all the selected machines of the product family.

\subsection{Sustainability and Manufacturing}

The sustainable production system is defined by Allwood et al. (2008) as: "a system able to transform materials without (i) greenhouse gas emissions and (ii) use of unsustainable or toxic materials or (iii) produce waste". Some research directions were identified leading to solutions for sustainable manufacturing (Bi, 2011). Jayal et al. (2010) and Jawahir et al. (2009) stated that achieving sustainability goes through optimising not only the product or its manufacturing process but also the entire supply chain as a whole. More concretely, Mouzon et al. (2007), Yusta et al. (2010), Fang et al. (2011), Küster et al. (2013) and Moon et al. (2013) tried to integrate energy consumption into the total production cost using time of use (TOU) tariffs in scheduling problems. Choi \& Xirouchakis (2015) proposed a model that takes into account the environmental and energy consumption effects of capacity change in a reconfigurable and flexible production environment. Afrin et al. (2016) attempted to minimise the greenhouse gases emitted during manufacturing for a production line with rotary transfer and turrets.

More recently, a quantitative framework is proposed by Stoycheva et al. (2018) for sustainable manufacturing. The authors described its application to the automotive industry and demonstrated that the sustainability objectives can be enhanced by material alternatives. Zhu et al. (2018) published a rich literature review dedicated to the used modeling techniques to address the sustainable food supply chain (SFSC) issues. The authors studied the main challenges that emerge from modeling sustainability.

\subsection{Sustainability and $R M S$}

Touzout \& Benyoucef (2018b) addressed the sustainable multi-objective multi-unit process plan generation in reconfigurable manufacturing environment, where the amount of greenhouse gases (GHG) emitted during the production process is minimized in addition to manufacturing criteria such as cost and time. They developed an iterative multi-objective integer linear programming (I-MOILP) and adapted NSGA-II and the archived multi-objective simulated-annealing (AMOSA) to solve the problem and they studied the influence of the probabilities of genetic operators on the convergence of the adapted NSGA-II.

More recently, Touzout \& Benyoucef (2019) proposed and compared three hybrid heuristics namely: repetitive single-unit process plan heuristic (RSUPP), iterated local search on single-unit process plans heuristic (LSSUPP) and archive-based iterated local search heuristic (ABILS) to solve the multi-unit process plan generation problem in RMS taking into consideration the minimization of the maximum machines exploitation time and the classical total production cost and the total completion time. Massimi et al. (2020) developed a non-linear mathematical model to optimize the energy consumption in an RMS through a redefinition of 
two of its core characteristics, namely modularity and integrability. The model minimizes the total energy consumption of the system by selecting the most suitable modular machines from a set of candidate reconfigurable machines. The optimization problem is addressed using an exhaustive search heuristic algorithm, and demonstrated through simple illustrative numerical examples. Battaïa et al. (2020) showed how the RMS's concepts can lead to the design of sustainable and energy efficient manufacturing systems. Two questions are considered: how to increase the life cycle of a RMS (including how to use in an optimal manner their components after the end of life)? and how to decrease the emissions and energy consumption during the life cycle. They concluded that both questions should be analysed at the RMS design stage and an intelligent choice of technologies and modules to use could be a solution of these problems.

Significant progresses have been made in developing approaches to address RMS design problems. Nevertheless, little research works are dedicated to sustainable RMS problems in general, and to sustainable process plan generation in particular. In this paper, we propose to adapt four evolutionary approaches respectively, WGA, RWGA, NSGA-II and NSGA-III to solve the sustainable RMS design problem (ie. reconfigurable machines and tools selection). Rich experimental results are presented and analysed using three metrics showing the superiority of NSGA-III.

\section{Problem Description and Formulation}

In the following, we describe more in details the problem under consideration and present its mathematical formulation.

\subsection{Problem Description}

Let us consider a single unit of a product to be manufactured in a reconfigurable environment. The product is defined by a set of features to be achieved. Each feature requests a set of operations linked by precedence constraints, as illustrated in Figure 1. From the example, we can see that we have four features:

$F 1=\left\{O P_{1}\right\}, F 2=\left\{O P_{2}, O P_{3}\right\}, F 3=\left\{O P_{4}, O P_{5}, O P_{6}\right\}$ and $F 4=\left\{O P_{7}\right\}$. Moreover, three key data define an operation: the precedence constraints, the set of candidate tools and the tool approach directions (TADs) (i.e., $\pm y \pm, \mathrm{z} \pm$ ). Table 1 shows the required TADS and tools for the operations of our example.

Once the requirements of the operation are identified, a machine is able to perform a certain number of operations. Given that, for each machine, the sets of available configurations and compatible tools are identified. Thus, each operation $O P_{i}$ requires an association of machine-configuration-tool $(M, C, T)$ called triplet $T O_{i}$. Table 2 presents the TADS, configurations and tools that each machine can offers.

The generation of process plan consists of sequencing the operations to be performed on the machines under the configuration, using the tool, through the precedence graph as well as the triplets to perform each operation in the sequence. Table 3 presents an example of a generated process plan of our example. 

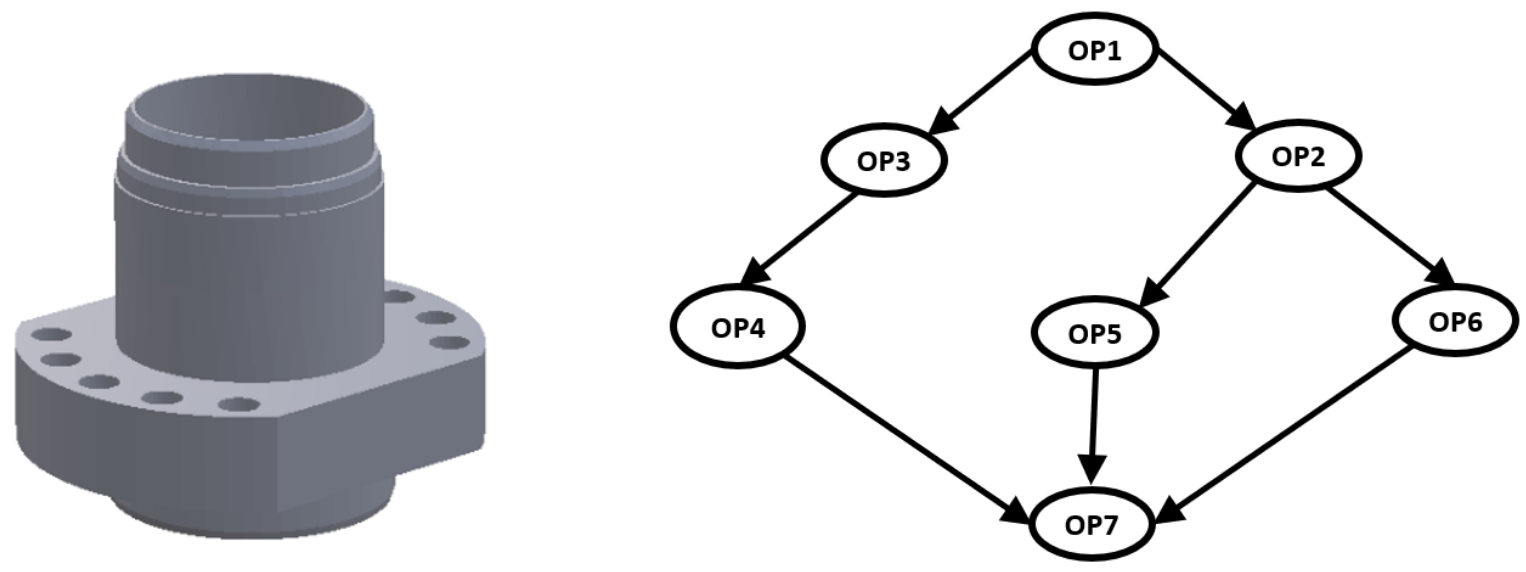

Figure 1: An illustrative product schema and operation precedence graph

Table 1: Operations requirements

\begin{tabular}{|c|c|c|c|c|c|c|c|}
\hline \multirow[t]{2}{*}{$\mathrm{OP}$} & \multicolumn{6}{|c|}{ TAD } & \multirow[t]{2}{*}{ Tools } \\
\hline & $+\mathrm{X}$ & $+\mathrm{Y}$ & $+\mathrm{Z}$ & $-\mathrm{X}$ & $-Y$ & $-Z$ & \\
\hline$O p_{1}$ & $\times$ & $\times$ & $\times$ & & $\times$ & & $\mathrm{T} 2$ \\
\hline$O p_{2}$ & $\times$ & & & & & $\times$ & $\mathrm{T} 3$ \\
\hline$O p_{3}$ & & & $\times$ & & & & $\mathrm{T} 1$ \\
\hline$O p_{4}$ & $\times$ & $\times$ & & & $\times$ & & $\mathrm{T} 1$ \\
\hline$O p_{5}$ & & & & & & $x$ & $\mathrm{~T} 3$ \\
\hline$O p_{6}$ & & & $\times$ & $\times$ & & $\times$ & $\mathrm{T} 2$ \\
\hline$O p_{7}$ & $\times$ & & $\times$ & $x$ & & & $\mathrm{~T} 3$ \\
\hline
\end{tabular}


Table 2: Machines requirements

\begin{tabular}{|c|c|c|c|c|c|c|c|c|}
\hline \multirow[t]{2}{*}{ Ms } & \multirow[t]{2}{*}{ Cs } & \multicolumn{6}{|c|}{ TAD } & \multirow[t]{2}{*}{ Tools } \\
\hline & & $+\mathrm{X}$ & $+\mathrm{Y}$ & $+\mathrm{Z}$ & $-\mathrm{X}$ & $-Y$ & $-Z$ & \\
\hline$M_{1}$ & $\begin{array}{l}C_{1} \\
C_{2}\end{array}$ & $\times$ & & $\times$ & $x$ & $x$ & $\times$ & $\mathrm{T} 2, \mathrm{~T} 3$ \\
\hline$M_{2}$ & $\begin{array}{l}C_{1} \\
C_{2} \\
C_{3}\end{array}$ & $\times$ & $\begin{array}{l}\times \\
\times\end{array}$ & $\begin{array}{l}x \\
\times\end{array}$ & $\times$ & $\times$ & $\begin{array}{l}\times \\
\times\end{array}$ & T1,T3 \\
\hline$M_{3}$ & $C_{1}$ & $\times$ & $\times$ & $\times$ & $\times$ & $\times$ & & $\mathrm{T} 1, \mathrm{~T} 2$ \\
\hline$M_{4}$ & $\begin{array}{l}C_{1} \\
C_{2}\end{array}$ & & $x$ & $\begin{array}{l}\times \\
\times\end{array}$ & $\times$ & $\begin{array}{l}\times \\
\times\end{array}$ & $\begin{array}{l}\times \\
\times\end{array}$ & $\mathrm{T} 1, \mathrm{~T} 2$ \\
\hline$M_{5}$ & $C_{1}$ & & $\times$ & $x$ & $\times$ & & & T3 \\
\hline
\end{tabular}

Table 3: Illustrative structure of a process plan

\begin{tabular}{|c|ccccccc|}
\hline Operation & $O P_{1}$ & $O P_{3}$ & $O P_{4}$ & $O P_{2}$ & $O P_{6}$ & $O P_{5}$ & $O P_{7}$ \\
\hline Machine & $M_{3}$ & $M_{4}$ & $M_{2}$ & $M_{1}$ & $M_{4}$ & $M_{2}$ & $M_{2}$ \\
Configuration & $C_{1}$ & $C_{1}$ & $C_{1}$ & $C_{2}$ & $C_{2}$ & $C_{2}$ & $C_{3}$ \\
Tool & $T_{2}$ & $T_{1}$ & $T_{1}$ & $T_{3}$ & $T_{2}$ & $T_{3}$ & $T_{3}$ \\
\hline
\end{tabular}

In the following, the generated process plans should satisfy the manufacturing requirements with respect to manufacturing criteria, respectively, total production cost and the total completion time. Moreover, the sustainability criteria cover both the greenhouse gases (GHG) emissions and the liquid hazardous wastes. To summarize, four criteria are minimized in this study:

1. The total production cost: It comprises the cost of changing machines, configurations, tools and the cost of processing, cost of the emitted greenhouse gases and cost of the hazardous liquid waste.

2. The total production time: It consists of the engaged time in changing machines, configurations, tools and the processing time of the operations.

3. The waste: It comprises the hazardous liquid waste during processing of the operations, including:

- wastes oils/water, hydrocarbons/water mixtures, emulsions;

- wastes from the production, formulation and use of resins, latex, plasticizers, glues/adhesives;

- wastes resulting from surface treatment of metals and plastics;

- residues arising from industrial waste disposal operations. 
4. The green house gases (GHG) emissions during the total production process.

\subsection{Mathematical Formulation}

\section{Parameters}

$n \quad$ Number of operations

$O P \quad$ Set of operations

$i, i^{\prime} \quad$ Index of operations

$P R_{i} \quad$ Set of predecessors of operation $O P_{i}$

$m \quad$ Number of machines

$M \quad$ Set of machines

$j, j^{\prime} \quad$ Index of machine

$G \quad$ Set of greenhouse gases

$g \quad$ Index of greenhouse gases

$L \quad$ Available liquid

$l_{i, t} \quad$ Required liquid for operation $O P_{i}$ when using triplet $t$ per time unit

$E P_{i, t} \quad$ Estimated hazardous liquid waste for operation $O P_{i}$ when using triplet $t$

$f_{e f} \quad$ Emission factor for electricity consumption

$f_{i, g} \quad$ Operation $O P_{i}$ emitting greenhouse gas type $g$ per time unit

$t, t^{\prime} \quad$ Index of triplet

$T O_{i} \quad$ Set of available triplets for operation $O P_{i}$

$T M_{j} \quad$ Set of available triplets using machine $M_{j}$

$T \quad$ Set of triplets, where $T=T O_{i} \cup T M_{j}$

$c, c^{\prime} \quad$ Index of configurations

$t l, t l^{\prime} \quad$ Index of tools

$p, p^{\prime} \quad$ Index of positions in the sequence

$G W P_{g} \quad$ Global warning potential for emitted greenhouse gas type $g$

Cost Parameters

$C C M_{j, j^{\prime}} \quad$ Machine changeover cost per time unit

$C C C_{c, c^{\prime}} \quad$ Configuration changeover cost per time unit

$C C T_{t l, t l^{\prime}} \quad$ Tool changeover cost per time unit

$P c_{i, t} \quad$ Operation $O P_{i}$ processing cost when using triplet $t$ per time unit

$D C_{G H G} \quad$ Disposal cost of the emitted greenhouse gases

$D C_{L H W} \quad$ Disposal cost of the hazardous liquid waste 
Time Parameters

$T C M_{j, j^{\prime}} \quad$ Machine changeover time

$T C C_{c, c^{\prime}} \quad$ Configuration changeover time

$T C T_{t l, t l^{\prime}} \quad$ Tool changeover time

$T p_{i, t} \quad$ Operation $O P_{i}$ processing time when using triplet $t$

\section{Energy Parameters}

$E C M_{j, j^{\prime}} \quad$ Machine changeover energy per time unit

$E C C_{c, c^{\prime}} \quad$ Configuration changeover energy per time unit

$E C T_{t l, t l^{\prime}} \quad$ Tool changeover energy

$E P_{i, t} \quad$ Operation $O P_{i}$ processing energy when using triplet $t$ per time unit

$I E C_{j} \quad$ Initial energy consumption of machine $M_{j}$

\section{Decision Variables}

The following decision variables are used:

$x_{i, p}^{t}=1$ if operation $O P_{i}$ is using triplet $t$ at the $p^{t h}$ position, 0 otherwise.

$y_{p, t}^{m}=1$ if machine $M_{j}$ is using triplet $t$ at the $p^{t h}$ position, 0 otherwise.

$M C_{p}^{p-1}\left(j, j^{\prime}\right)=1$ if there has been a change from machine $M_{j}$ to machine $M_{j}^{\prime}$ between positions $p-1$ and $p, 0$ otherwise.

$T C_{p}^{j, p-1}\left(t, t^{\prime}\right)=1$ if there has been a change from triplet $t$ to triplet $t^{\prime}$ of machine $M_{j}$ between positions $p-1$ and $p, 0$ otherwise.

\section{Objective Functions}

Our problem can be formulated as a non-linear multi-objective integer program (NL-MOIP), where four objectives are optimized:

1. The total production cost $f_{c}$ :

Equation (1) represents the total production cost to be minimized. It includes the following costs: machine changeover cost, configuration changeover cost, tool changeover cost, processing cost, emitted greenhouse gases cost and disposal cost of the emitted hazardous waste during the production.

$$
\begin{aligned}
f_{c}= & \sum_{p=1}^{n} \sum_{i=1}^{n} \sum_{t \in T O_{i}} x_{i, p}^{t} \times P c_{i, t} \times P t_{i, t}+ \\
& \sum_{p=2}^{n} \sum_{j=1}^{m} \sum_{j^{\prime}=1}^{m} M C_{p}^{p-1}\left(j, j^{\prime}\right) \times C C M_{j, j^{\prime}} \times T C M j, j^{\prime}+ \\
& \sum_{p=2}^{n} \sum_{j=1}^{m} \sum_{t \in M_{j}} \sum_{t^{\prime} \in M_{j}} T C_{p}^{j, p-1} \times\left(C C T_{t l, t l^{\prime}} T C T_{t l, t l^{\prime}}+\right. \\
& \left.C C C_{c, c^{\prime}} \times T C C_{c, c^{\prime}}\right)+\left(D C_{G H G} \times f_{G H G}+D C_{L W H} \times f_{L H W}\right)
\end{aligned}
$$


2. The total production time $f_{t}$ :

Equation (2) calculates the total production time to be minimized. It includes the following times: machine changeover time, configuration changeover time, tool changeover time and processing time.

$$
\begin{aligned}
f_{t}= & \sum_{p=1}^{n} \sum_{i=1}^{n} \sum_{t \in T O_{i}} x_{i, p}^{t} \times E P_{i, t}+ \\
& \sum_{p=2}^{n} \sum_{j=1}^{m} \sum_{j^{\prime}=1}^{m} M C_{p}^{p-1} \times T C M_{j, j^{\prime}}+ \\
& \sum_{p=2}^{n} \sum_{j=1}^{m} \sum_{t \in M_{j}} \sum_{t^{\prime} \in M_{j}} T C_{p}^{j, p-1}\left(t, t^{\prime}\right) \times\left(T C C_{c, c^{\prime}}+T C T_{t l, t l^{\prime}}\right)
\end{aligned}
$$

3. The amount of hazardous liquid waste $f_{L H W}$ :

Equation (3) defines the amount of hazardous liquid waste to be minimized.

$$
f_{L H W}=\sum_{p=1}^{n} \sum_{i=1}^{n} \sum_{t \in T O_{i}} x_{i, p}^{t} \times l_{i, t} \times T P_{i, t} \times E P_{i, t}
$$

4. The amount of greenhouse gases emitted $f_{G H G}$ :

Equation (4) defines the amount of greenhouse gases emitted during the manufacturing process to be minimized. It is composed of two parts. The first considers the energy consumption taking into account the emission factor for consumed electricity. The second considers the emitted gases taking into account the factor of global warning potential (GWP). In this research work, GWP factor is used to convert emissions of the other greenhouse gases into $\mathrm{CO}_{2}$ equivalents.

$$
f_{G H G}=f_{e f} \times f_{E C}+\sum_{p=1}^{n} \sum_{i=1}^{n} \sum_{t \in T O_{i}} \sum_{g \in G} x_{i, p}^{t} \times T P_{i, t} \times f_{i, g} \times G W P_{g}
$$

Equations (5) describe more in details how to compute the total energy consumption during the production $f_{E C}$.

$$
\begin{aligned}
f_{E C}= & \sum_{p=1}^{n} \sum_{i=1}^{n} \sum_{j=1}^{m} \sum_{t \in T O_{i}} y_{p, t}^{j} \times x_{i, p}^{t} \times I E C_{j}+ \\
& \sum_{p=1}^{n} \sum_{i=1}^{n} \sum_{t \in T O_{i}} x_{i, p}^{t} \times E P_{i, t} \times T p_{i, t}+ \\
& \sum_{p=2}^{n} \sum_{j=1}^{n} \sum_{j^{\prime}=1}^{m} M C_{p}^{p-1}\left(j, j^{\prime}\right) \times E C M_{j, j^{\prime}} \times T C M_{j, j^{\prime}}+ \\
& \sum_{p=2}^{n} \sum_{j=1}^{m} \sum_{t \in T M_{j}} \sum_{t^{\prime} \in T M_{j^{\prime}}} T C_{p}^{j, p-1}\left(t, t^{\prime}\right) \times \\
& \left(T T C_{t l, t l^{\prime}} \times E T C_{t l, t l^{\prime}}+T C C_{c, c^{\prime}}+E C C_{c, c^{\prime}}\right)
\end{aligned}
$$


We can see that, $f_{E C}$ is a non-linear function. In order to transform it to a linear one, we can use the following equations:

$$
\begin{array}{ll}
y_{p, t}^{j} & \times x_{i, p}^{t}=z \\
\text { S.t }: & z \leq x_{i, p}^{t} \\
& z \leq y_{p, t}^{j} \\
& z \geq y_{p, t}^{j}+x_{i, p}^{t}-1 \\
& z \in\{0,1\}
\end{array}
$$

\subsection{Model}

The model is therefore represented as follow as:

$$
\begin{aligned}
& \min f_{c} \\
& \min f_{t} \\
& \min f_{L H W} \\
& \min f_{G H G} \\
& \sum_{i=1}^{n} \sum_{t \in T O_{i}} x_{i, p}^{t} \\
& =1 \quad \forall p=1 \ldots n \\
& \sum_{p=1}^{n} \sum_{t \in T O_{i}} x_{i, p}^{t} \\
& =1 \quad \forall i=1 \ldots n \\
& \sum_{t \in T O_{i}} x_{i, p}^{t} \times\left|P R_{i}\right| \\
& \leq \sum_{p^{\prime}=1}^{P^{\prime}-1} \sum_{t^{\prime} \in T O_{i}^{\prime}} x_{i^{\prime}, p^{\prime}}^{t^{\prime}} \quad \forall i=1 \ldots n, \forall p=1 \ldots n \\
& \sum_{j=1}^{m} \sum_{t \in T_{M j}} y_{p, t}^{j} \\
& =1 \quad \forall p=1 \ldots n, \forall j=1 \ldots m \\
& y_{p, t}^{j} \\
& \geq x_{i, p}^{t} \\
& \forall p=1 \ldots n, \forall j=1 \ldots m \\
& \sum_{i=1}^{n} x_{i, p}^{t}+\sum_{i=1}^{n} x_{i, p-1}^{t} \\
& \leq \quad M C_{p}^{p-1}\left(j, j^{\prime}\right)+1 \quad \forall p=2 \ldots n, \forall t, t^{\prime} \in T \\
& y_{p, t}^{j}+y_{p-1, t^{\prime}}^{j} \\
& \leq \quad T C_{p}^{j, p-1}\left(t, t^{\prime}\right)+1 \quad \forall p=2 \ldots n, \forall j=1 \ldots m, \forall t, t^{\prime} \in T M_{j} \\
& \begin{array}{cl}
\sum_{t, t^{\prime} \in T M_{j}} T C_{p}^{j, p-1}\left(t, t^{\prime}\right) & =1 \\
\sum_{p=1}^{n} \sum_{i=1}^{n} \sum_{t \in T O_{i}} x_{i, p}^{t,} \times l_{i, t} \times T P_{i, t} & \leq L
\end{array} \\
& x_{i, p}^{t,} \in\{0,1\} \\
& y_{p, t}^{j} \in\{0,1\} \\
& T C_{p}^{j, p-1}\left(t, t^{\prime}\right) \in\{0,1\} \\
& M C_{p}^{p-1}\left(j, j^{\prime}\right) \in\{0,1\}
\end{aligned}
$$


Constraint (6) states that each position of the process plan is processed by only one operation. Constraint (7) imposes that each operation is processed only once. Constraint (8) considers that an operation is processed if all the predecessors operations are processed. Constraint (9) represents that each machine can use only one configuration and one tool at once. Constraint (10) states that the requirement of configuration and tool in position $p$ for machine $M_{j}$. Constraint (11) defines if there is a change of machines between the position $p-1$ and $p$. Constraint (12) is used to show if there is a change of configuration and/or tool between the position $p-1$ and $p$. Constraint (13) states that there's only one change of configuration and/or tool between positions $p-1$ and $p$. Constraint (14) considers the respect of the limited liquid storage of the manufacturer.

\subsection{Complexity}

In a reconfigurable manufacturing environment, the process plan generation problem is NP-hard. By eliminating the aspect where for each operation, an optimal machine, configuration and tool need to be designated as well as the precedence constraints, an instance from the well-known travelling salesman problem (TSP) can be reduced in a polynomial time to an instance of our problem. Hence, the operations in this case will represent the nodes of the network and the objective will be to find the optimal sequence (route) in terms of time or cost, where the time/cost from one node to another corresponds to the changeovertime/changeover-cost. Since the TSP is NP-hard, the problem addressed in this study is also NP-hard.

\section{Proposed Approaches}

In order to generate optimal process plans with respect to sustainable and classical manufacturing criteria, we attempt to use four meta-heuristic approaches respectively non dominated sorting genetic algorithm II (NSGA-II), non dominated sorting genetic algorithm III (NSGA-III), weighted genetic algorithm (WGA) and random weighted genetic algorithm (RWGA).

\subsection{Solution Representation and Evaluation}

To be able to manipulate the solutions (process plans in our case) and to obtain acceptable results using the adapted evolutionary approaches, each solution is represented in the form of a matrix with four rows (Operation, Machine, Configuration and Tool) and $n$ columns (number of operations) as the form shown in Table 3. It is interpreted from the left to the right, column by column, for example, the first column should be read as follows: the operation $O P 1$ is executed by the machine $M 3$, under the configuration $C 1$, using the tool $T 2$.

A key step is the coding of solutions, which aims to make them more manipulative. The structure of a chromosome (solution) is illustrated by regrouping machines, configurations and tools under triplets. A chromosome is encoded as $2 \times n$ matrix where its elements take real values between 0 and 1,1 not included. As shown in Table 4, where the first and second row represent, respectively, a coded of the operation index and the triplet index. 
Table 4: Representation of the encoded process plan

\begin{tabular}{|c|ccccccc|}
\hline Operation & 0.34 & 0.45 & 0.76 & 0.12 & 0.55 & 0.87 & 0.62 \\
\hline Triplet & 0.87 & 0.08 & 0.67 & 0.21 & 0.17 & 0.39 & 0.56 \\
\hline
\end{tabular}

Evidently this solution coded must be decoded. Column by column, starting with a generation of the operations sequences with respect of the precedence constraints. Then, the sets of triplets are associated to each of the operations in random generated sequences. In Algorithm 1, a detailed description of the decoding procedure is presented for decoding the coded process plan in Table 4 to provides the process plan illustrated in Table 3.

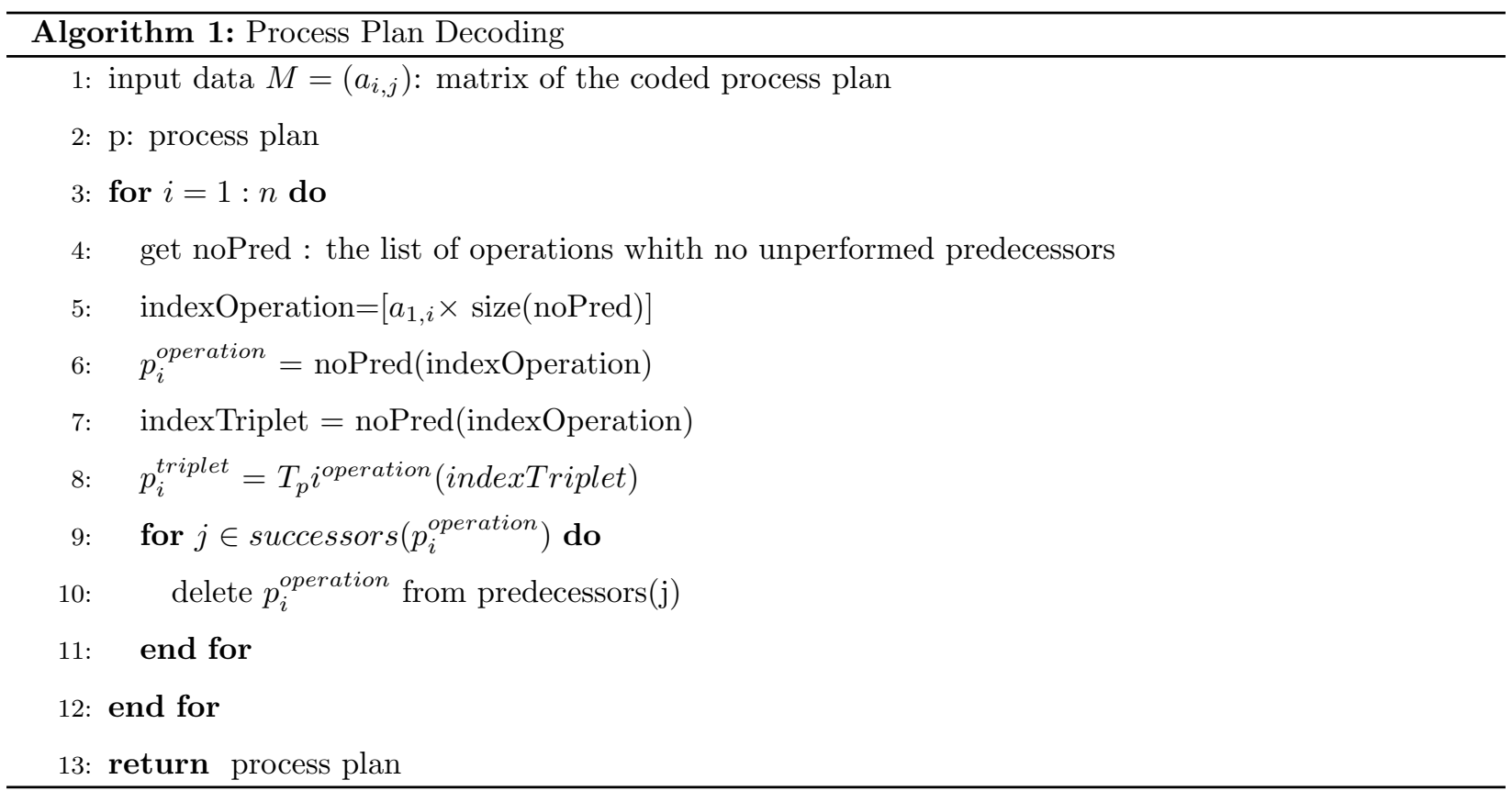

The obtained set of process plan in Table 4 is computed by using the objective functions formulated in Section 3. Since the optimization of our problem is guided by four objective functions: total production cost, total production time, the amount of hazardous liquid waste and the amount of greenhouse gases emitted, a Pareto Front of the non dominated solutions/process plans is generated.

\subsection{Genetic Operators}

In this study, two genetic operators namely crossover and mutation are used.

- Crossover: it is the most important phase in a genetic algorithm. Randomly, a crossover point is selected and two chromosomes exchange parts of their chains to create new chromosomes called offspring until the point of crossover is attained. Figure 2 illustrates examples of crossover operations. 


\begin{tabular}{|c|c|c|c|c|c|c|c|}
\hline \multirow{2}{*}{ Parent 1} & 0.34 & 0.45 & 0.76 & 0.12 & 0.55 & 0.87 & 0.62 \\
\hline & 0.48 & 0.87 & 0.11 & 0.56 & 0.63 & 0.28 & 0.05 \\
\hline \multirow{2}{*}{ Parent 2} & 0.23 & 0.57 & 0.17 & 0.88 & 0.79 & 0.68 & 0.04 \\
\hline & 0.69 & 0.21 & 0.83 & 0.09 & 0.17 & 0.52 & 0.79 \\
\hline \multirow{2}{*}{ Child 1} & 0.34 & 0.45 & 0.76 & 0.12 & 0.79 & 0.68 & 0.04 \\
\hline & 0.48 & 0.87 & 0.11 & 0.56 & 0.17 & 0.52 & 0.79 \\
\hline \multirow{2}{*}{ Child 2} & 0.23 & 0.57 & 0.17 & 0.88 & 0.55 & 0.87 & 0.62 \\
\hline & 0.69 & 0.21 & 0.83 & 0.09 & 0.63 & 0.28 & 0.05 \\
\hline
\end{tabular}

Figure 2: Illustrative Crossover operations

- Mutation: it consists of randomly modifying one gene from the new offspring created from a given chromosome. Provided that the retained generated children still a feasible solution, which will be evaluated by using the sets of possible sequences of operations and sets of possible triplets. Figure 3 illustrates examples of mutation operations.

Child 1

\begin{tabular}{|l|l|l|l|l|l|l|}
\hline $\mathbf{0 . 3 4}$ & 0.45 & $\mathbf{0 . 7 6}$ & $\mathbf{0 . 1 2}$ & 0.55 & $\mathbf{0 . 8 7}$ & $\mathbf{0 . 6 2}$ \\
\hline $\mathbf{0 . 4 8}$ & 0.87 & $\mathbf{0 . 1 1}$ & $\mathbf{0 . 5 6}$ & 0.63 & $\mathbf{0 . 2 8}$ & $\mathbf{0 . 0 5}$ \\
\hline
\end{tabular}

\begin{tabular}{|l|l|l|l|l|l|l|}
\hline $\mathbf{0 . 3 4}$ & 0.55 & $\mathbf{0 . 7 6}$ & $\mathbf{0 . 1 2}$ & 0.45 & $\mathbf{0 . 8 7}$ & $\mathbf{0 . 6 2}$ \\
\hline $\mathbf{0 . 4 8}$ & 0.63 & $\mathbf{0 . 1 1}$ & $\mathbf{0 . 5 6}$ & 0.87 & $\mathbf{0 . 2 8}$ & $\mathbf{0 . 0 5}$ \\
\hline
\end{tabular}

Figure 3: Illustrative mutation operations

\subsection{Adapted Evolutionary Algorithms}

In this section, we describe more in details the adapted multi-objective evolutionary approaches namely, WGA, RWGA, NSGA-II and NSGA-III to solve our problem. 


\subsubsection{Weighted Genetic Algorithm (WGA)}

WGA is a classical multi-objective evolutionary based approach, where the decision-maker assigns weights or priorities to the different objectives. Each objective $i$ is associated with a weight $w_{i}$ such that $0 \leq w_{i} \leq 1$ and $\sum_{i=1}^{K} w_{i}=1$, where $K$ is the number of objectives. In our case, for each objective $w_{i}=0.25$ and

$\sum_{i=1}^{4} w_{i}=1$. At each generation, WGA works as a single objective function during the selection phase by computing the overall fitness of the objectives as depicted in Equation (6).

$$
f(x)=w_{1} \times f_{c}(x)+w_{2} \times f_{t}(x)+w_{3} \times f_{L H W}(x)+w_{4} \times f_{G H G}(x)
$$

The adapted WGA consists in the following five steps:

Step 1 (Initialization): Generate an initial population P.

Step 2 (Evaluation): Evaluate the fitness function of each solution $\mathrm{x} \in P_{t}$ using Equation (6).

Step3 (Selection): Select parents based on ranking the fitness function value assigned in step 2.

Step 4 (crossover and mutation): Apply crossover on the selected parent pairs to create $N$ offspring. Mutate offspring with a predefined mutation rate. Copy all offspring to $P_{t+1}$.

Step 5: If the stopping condition is not satisfied, set $t=t+1$ and go to Step 2. Otherwise STOP.

\subsubsection{Random Weighted Genetic Algorithm (RWGA)}

RWGA was proposed by Murata et al. (1996). It is based on a weighted sum of multiple objective functions, where a normalized weight vector randomly generated is used for each solution during the selection phase at each generation. Let us consider:

$E=$ external archive to store non-dominated solutions found during the search so far.

$n_{E}=$ number of elitist solutions immigrating from $E$ to $P$ in each generation.

More detailed descriptions of the RWGA is presented in (Konak et al., 2006). A brief description of the adapted RWGA is summarized in the following six steps:

Step 1 (Initialization): Generate an initial population P.

Step 2 (Evaluation): Evaluate the fitness function of each solution $x \in P_{t}$ by performing the following steps:

Step 2.1: Generate a random number $u_{k}$ in $[0,1]$ for each objective $k, k=1 \ldots K$.

Step 2.2: Calculate the random weight of each objective $k$ as : $w_{k}=\left(\frac{1}{u_{k}}\right) \sum_{i=1}^{K} u_{i}$

Step 2.3: Calculate the fitness of solution $x$ as :

$$
f(x)=\sum_{i=1}^{K} w_{i} \times f_{i}(x)
$$


Step3 (Selection): Select parents according to the selection probability $P(x)$ associated to each solution $x \in P_{t}$ as:

$$
P(x)=\frac{f(x)-f_{\text {min }}}{\sum_{y \in P_{t}}\left(f(y)-f_{\text {min }}\right)}
$$

Where $: f_{\min }=\min \left\{f(x) / x \in P_{t}\right\}$

Step 4 (Crossover and Mutation): Apply crossover on the selected parent pairs to create $N$ offspring. Mutate offspring with a predefined mutation rate. Copy all offspring to $P_{t+1}$.

Step 5: Randomly remove $n_{E}$ solutions from $P_{t+1}$ and add the same number of solutions from $E$ to $P_{t+1}$.

Step 6: If the stopping condition is not satisfied, set $t=t+1$ and go to Step 2. Otherwise, return to E.

\subsubsection{Non Dominated Sorting Genetic Algorithm II (NSGA-II)}

NSGA-II is a revised version of the Non dominated Sorting Genetic Algorithm (NSGA) (Srinivas \& Deb, 1995), developed by Deb et al. (2002). The NSGA-II mechanism begins by ranking the solutions according to their non domination score to get a set of Pareto front solutions. Then, using the crowding distance technique to maintain the diversity of solutions on the Pareto front, applied on the last front to complete the next generation parent population size.

Algorithm 2 presents the main steps of NSGA-II. Furthermore, for clear descriptions of the used coded process plan as well as the mutation and the crossover operators, refer to Touzout \& Benyoucef (2018b). 


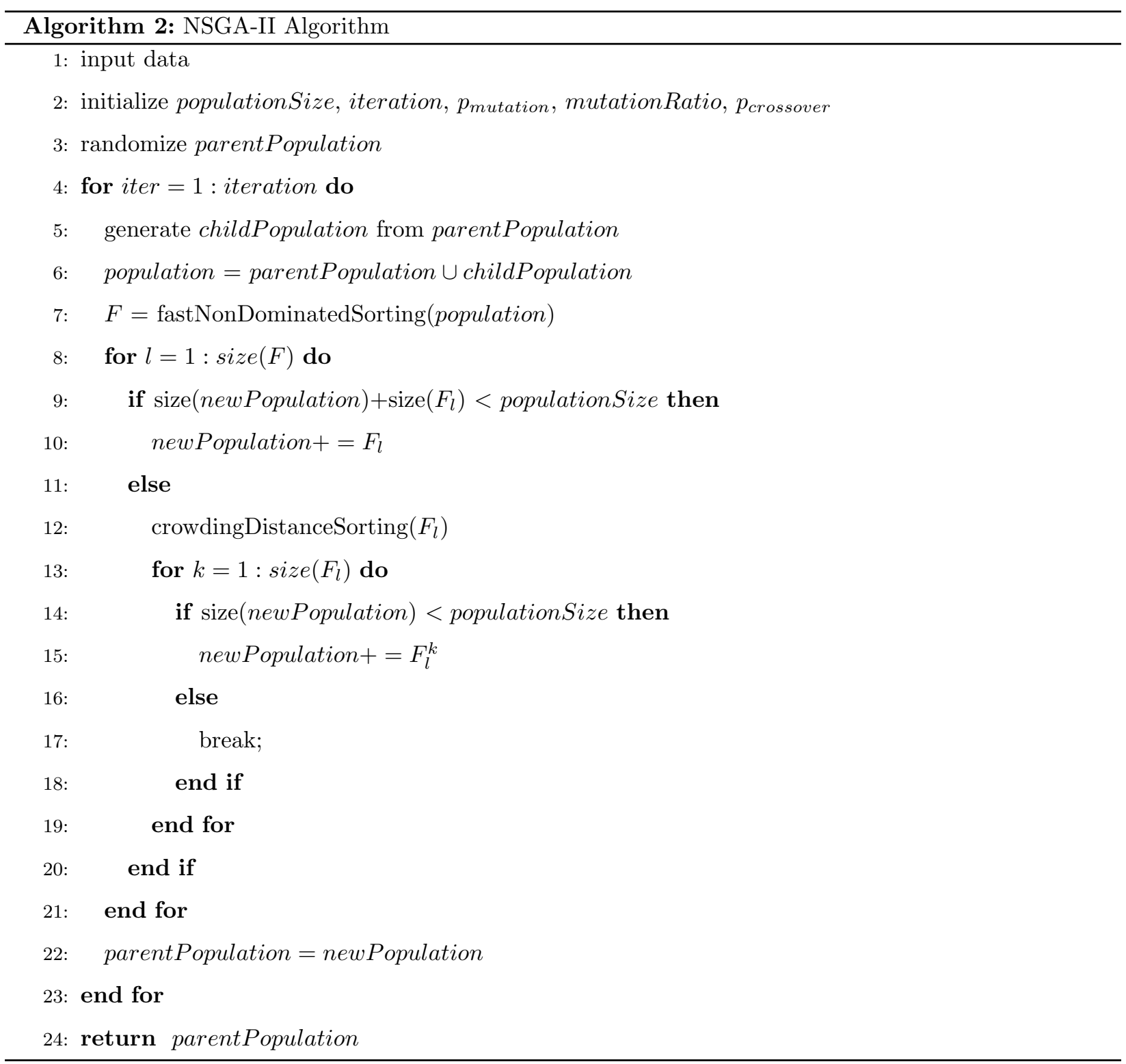

4.3.4. Non Dominated Sorting Genetic Algorithm III (NSGA-III)

NSGA-III is an extension of NSGA-II, developed by Deb \& Jain (2014). It is designed to improve the ability to solve the multi-objective optimization problem by changing the selection mechanism. Instead of the traditional crowding operator used in NSGA-II, NSGA-III adopts a reference point based niche mechanism to guide population to approach the diversity of the Pareto fronts. In order to achieve this, objective values and reference points are first normalized to have an identical range.

Note that the same procedures used for NSGA-II are being considered for initial population, crossover and mutation operators for NSGA-III. 


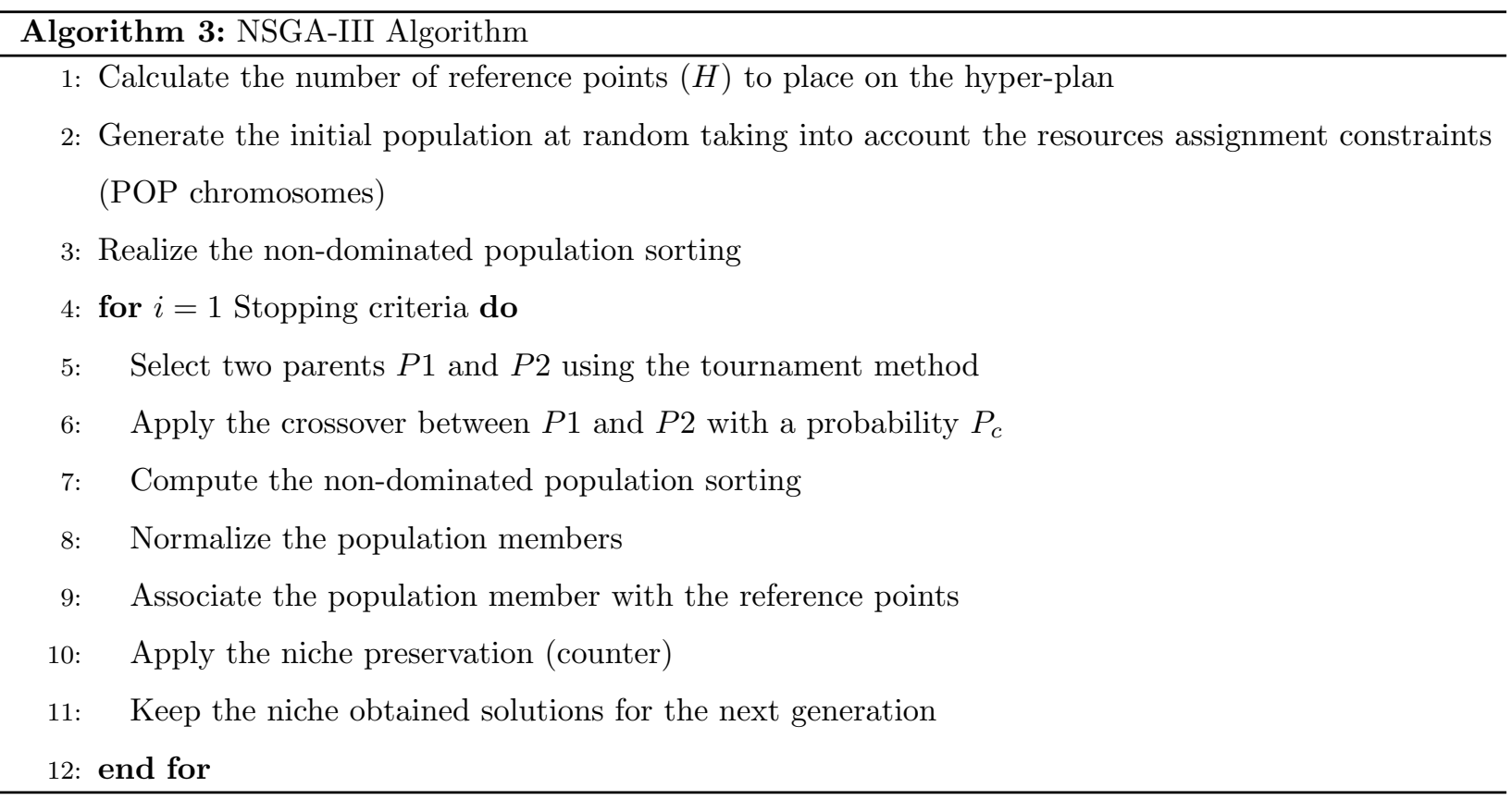

\subsection{TOPSIS}

Technique for order preference by similarity to ideal solution (TOPSIS) is on of the multi-criteria decision technique for the ranking and selection among a number of alternatives via the Euclidean distance, developed by Hwang et al. (1993). It is defined by seven steps, as follows:

\section{Step 1: Construct the decision matrix $X$ and the criteria weights $W$}

Let $\mathrm{X}=\left(x_{i j}\right)_{\alpha \times \beta}$ is the decision matrix and $W=\left[w_{1}, w_{2}, \ldots, w_{\beta}\right]$ weights vector given by the decision marker to present their preferences between criteria, with $\sum_{j=1}^{\beta} w_{j}=1$.

where:

$\alpha$ : number of alternatives.

$\beta$ : number of criteria.

\section{Step 2: Compute the normalized decision matrix}

for $i=1, \ldots, \alpha ; j=1, \ldots, \beta$

$$
r_{i j}=\frac{x_{i j}}{\sum_{i=1}^{\alpha} x_{i j}^{2}}
$$

Step 3: Compute the weighted normalized decision matrix $V=\left(v_{i j}\right)$

$$
v_{i j}=w_{j} \times x_{i j}
$$

where : $w_{j}$ is the weight of the $j^{t} h$ criterion.

Step 4: Determine the positive ideal $A^{+}$and negative ideal $A^{-}$

$$
A^{+}=\left(v_{1}^{+}, v_{2}^{+}, \ldots, v_{\beta}^{+}\right)=\left(\operatorname{Best}\left(v_{1 j}\right), \operatorname{Best}\left(v_{2 j}\right), \ldots, \operatorname{Best}\left(v_{\alpha j}\right)\right)
$$




$$
A^{-}=\left(v_{1}^{-}, v_{2}^{-}, \ldots, v_{\beta}^{-}\right)=\left(W \operatorname{orst}\left(v_{1 j}\right), W \operatorname{orst}\left(v_{2 j}\right), \ldots, W \operatorname{orst}\left(v_{\alpha j}\right)\right)
$$

Where :

$$
\begin{aligned}
\operatorname{Best}_{j}\left(v_{i j}\right) & = \begin{cases}\max \left(v_{i j}\right) & \text { if criteria } \mathrm{j} \text { is benefical } \\
\min \left(v_{i j}\right) & \text { if criteria } \mathrm{j} \text { is not benefical }\end{cases} \\
\text { Worst }_{j}\left(v_{i j}\right) & = \begin{cases}\min \left(v_{i j}\right) & \text { if criteria } \mathrm{j} \text { is benefical } \\
\max \left(v_{i j}\right) & \text { if criteria } \mathrm{j} \text { is not benefical }\end{cases}
\end{aligned}
$$

Step 5: For each alternative, compute the Eucledien distances from the positive ideal $A^{+}$and negative ideal $A^{-}$

$$
\begin{aligned}
& d_{i}^{+}=\sqrt{\sum_{j=1}^{\beta}\left(v_{i j}-v_{j}^{+}\right)^{2}}, i=1 \ldots \alpha \\
& d_{i}^{-}=\sqrt{\sum_{j=1}^{\beta}\left(v_{i j}-v_{j}^{-}\right)^{2}}, i=1 \ldots \alpha
\end{aligned}
$$

Step 6: Calculate the relative closeness of each alternative to the ideal solution

$$
C_{i}^{+}=\frac{d_{i}^{-}}{d_{i}^{-}+d_{i}^{+}}
$$

Where: $0 \leq C_{i}^{+} \leq 1$

\section{Step 7: Rank the alternatives according to the relative closeness}

The more $C_{i}^{+}$is important, the more desirable the alternative $i$ is.

\subsection{Comparison Metrics}

In this section, in order to analyse the obtained Pareto fronts and to compare the performances of the adapted evolutionary approaches, two well-known metrics, respectively hypervolume and spacing metric, are used.

\subsubsection{Hypervolume Metric (HV)}

The hypervolume metric (HV) (or s-metric) has been used by many authors (Huband et al., 2003), which is a performance metric for indicating the quality of non dominated solutions sets ND. It reflects the diversity and the uniformity of the nondominated solutions. This metric calculates the volume (in the objective space) covered by solutions that belong to a non dominated sets obtained by the proposed approaches and delimited from above by a reference point $r$ which is the anti-optimal point that is defined as the worst solution inside the objective space.

The mathematical expression of $\mathrm{HV}$ metric is calculated by the Equation 7:

$$
\left.H V(N D, r)=\wedge\left(\left\{\bigcup h\left(S_{l}\right)\right) \mid S_{t} \in N D, t=1, \ldots, \theta\right\}\right)
$$

Where: 
$\theta$ : is the number of solutions that are included in the Pareto front.

$\mu$ : is the number of objective functions

$S_{t}$ : the solution of a non-dominated solutions set and $t=\{1, \ldots, \theta\}$

$h\left(S_{t}\right)=\left|S_{t 1}-r_{1}\right| \times\left|S_{t 2}-r_{2}\right| \times\left|S_{t 3}-r_{3}\right| \times \cdots \times\left|S_{t \mu}-r_{\mu}\right|$

$\wedge($.$) : denotes the Lebesgue measure$

The larger the $\mathrm{HV}$ value is, the better the algorithm is.

\subsubsection{Spacing Metric (SM)}

Spacing metric is usually used to demonstrate the uniformity of attained Pareto frontier(how evenly the non dominated process plan are distributed along the Pareto front). Equation 8 calculates the Spacing metric:

$$
\text { Spacing }=\sqrt{\frac{1}{\Omega-1} \sum_{i=1}^{\Omega}\left(d_{i}-\bar{d}\right)^{2}}
$$

where:

$f_{1 i}, f_{2 i}, f_{3 i}$ and $f_{4 i}$ : respectively represent, the sustainability-metric, time and cost objective functions.

$\Omega$ : represents the number of non-dominated solutions in each frontier.

$d_{i}$ : represents the minimum distance between two solutions in the attained front Pareto and $\bar{d}$ is mean of the obtained $d_{i}$.

$$
\begin{aligned}
& d_{i}=\min \left\{\left|f_{1 i}-f_{1 j}\right|+\left|f_{2 i}-f_{2 j}\right|+\left|f_{3 i}-f_{3 j}\right|+\left|f_{4 i}-f_{4 j}\right|\right\} i, j=1,2, \ldots, \Omega, i \neq j \\
& \bar{d}=\frac{\sum_{i=1}^{\Omega}\left(d_{i}\right)}{\Omega}
\end{aligned}
$$

The less the spacing is, the more desirable is the value.

\subsection{Used GHG Parameters}

The emitted gases include the emissions from energy consumption and the type of operations. The emission factor for electricity consumption $\left(f_{e f}\right)$ is based on the covenant of mayors agreement (Koffi et al., 2017). Table 5 represents the national and European emission factors for consumed electricity. Where, Table 6 represents the GWP of Kyoto protocol greenhouse gases (Eurostat, 2010), GWP factor represents global warming potential and is used to convert emissions of other greenhouse gases into $\mathrm{CO}_{2}$ equivalents. 
Table 5: National and European emission factors for consumed electricity (Koffi, et al., 2017)

\begin{tabular}{|l|c|c|c|c|c|}
\hline Country & $\begin{array}{c}\text { Standard Emission } \\
\text { Factor } \\
\left(T C O_{2} / M W H\right)\end{array}$ & $\begin{array}{c}\text { LCA Emission Factor } \\
\left(T C O_{2}-E Q / M W H\right)\end{array}$ & Country & $\begin{array}{c}\text { Standard Emission } \\
\text { Factor } \\
\left(T C O_{2} / M W H\right)\end{array}$ & $\begin{array}{c}\text { LCA Emission Factor } \\
\left(T C O_{2}-E Q / M W H\right)\end{array}$ \\
\hline Austria & 0.209 & 0.310 & Sweden & 0.023 & 0.079 \\
\hline Belgium & 0.285 & 0.402 & Bulgaria & 0.819 & 0.906 \\
\hline Germany & 0.624 & 0.706 & Cyprus & 0.874 & 1.019 \\
\hline Denmark & 0.461 & 0.760 & Czech Republic & 0.950 & 0.802 \\
\hline Spain & 0.440 & 0.639 & Estonia & 0.908 & 1.593 \\
\hline Finland & 0.216 & 0.418 & Hungary & 0.566 & 0.678 \\
\hline France & 0.056 & 0.146 & Lithuania & 0.153 & 0.174 \\
\hline United Kingdom & 0.543 & 0.658 & Latvia & 0.109 & 0.563 \\
\hline Greece & 1.149 & 1.167 & Poland & 1.191 & 1.185 \\
\hline Ireland & 0.732 & 0.870 & Romania & 0.701 & 1.084 \\
\hline Italy & 0.483 & 0.708 & Slovenia & 0.557 & 0.602 \\
\hline Netherlands & 0.435 & 0.716 & Slovakia & 0.252 & 0.353 \\
\hline Portugal & 0.369 & 0.750 & EU-27 & 0.460 & 0.578 \\
\hline
\end{tabular}

Note: The standard emission factors following the Intergovernmental Panel on Climate Change (IPCC) principles are based on the carbon contents in the fuels. For simplicity, the emission factors presented here assume that all carbon in the fuel forms $\mathrm{CO}_{2}$. Life Cycle Assessment (LCA) emission factors take into account the overall life cycle of the energy carrier. This way of computation includes not only the emissions of the final combustion, but also all emissions of the supply chain. 
Table 6: Global Warming Potentials Of Kyoto Protocol Greenhouse Gases (Eurostat, 2010)

\begin{tabular}{|l|l|l|}
\hline Chemical Formula & Greenhouse Gas & Global Warming Potential $(G W P)_{(1)}$ \\
\hline $\mathrm{CO}_{2}$ & Carbon dioxide & 1 \\
\hline $\mathrm{CH}_{4}$ & Methane & 21 \\
\hline $\mathrm{N}_{2} \mathrm{O}$ & Nitrous oxide & 310 \\
\hline $\mathrm{HFCs}$ & Hydrofluorocarbons & $140\left(\mathrm{C}_{2} \mathrm{H}_{4} F_{2}\right)$ to $11700\left(C H F_{3}\right)$ \\
\hline $\mathrm{PFCs}$ & Perfluorocarbons & $5700\left(\mathrm{CF}_{4}\right)$ to $11900\left(\mathrm{C}_{2} F_{6}\right)$ \\
\hline $\mathrm{SF}_{6}$ & Sulphur hexafluoride & 23900 \\
\hline
\end{tabular}

Note $_{(1)}$ : In a 100-year time horizon. Reading guide: For example, one ton of methane equates to 21 tons of $\mathrm{CO}_{2}$.

\section{Experimental Results \& Analyses}

In this section, we describe our experiments results achieved with an Intel Core i3 $1.7 \mathrm{GHz}$ processor and 4 GB RAM and 4 GB RAM. The four approaches were implemented with a Java-Cplex. Using the single unit scenario. An instance is defined by the number of operations and the number of available reconfigurable machines and represented by nbOperations-nbMachines.

Initially, to evaluate the influence of genetic operators' probabilities on the convergence of NSGA-III, we study different scenarios and compare the cardinalities of the obtained Pareto fronts. In our case, a scenario is defined by the probability of its mutation operator (i.e., NSGA-III-10 is an adapted NSGA-III scenario where $10 \%$ of the childs population is generated by mutation operations, while the rest $90 \%$ is the result of crossover operations). Five scenarios are considered respectively NSGA-III-0, NSGA-III-10, NSGA-III-50, NSGA-III-90 and NSGA-III-100. In each scenario, the results are compared and analysed. Table 7 presents the cardinality of the Pareto front (i.e., number of Pareto optimal process plans) of each scenario in the case of 100 operations and 20 reconfigurable machines when the number of iterations attempts 2000 .

Table 7: The probabilities of genetic operators and cardinality of the Pareto fronts on the convergence of NSGA-III

\begin{tabular}{|c|c|c|c|c|c|}
\cline { 2 - 6 } \multicolumn{1}{c|}{} & $\begin{array}{c}\text { Scenario 1 } \\
\text { NSGA-III-0 }\end{array}$ & $\begin{array}{c}\text { Scenario 2 } \\
\text { NSGA-III-10 }\end{array}$ & $\begin{array}{c}\text { Scenario 3 } \\
\text { NSGA-III-50 }\end{array}$ & $\begin{array}{c}\text { Scenario 4 } \\
\text { NSGA-III-90 }\end{array}$ & $\begin{array}{c}\text { Scenario 5 } \\
\text { NSGA-III-100 }\end{array}$ \\
\hline Pmutation & 0 & 10 & 50 & 90 & 100 \\
\hline Pcrossover & 100 & 90 & 50 & 10 & 0 \\
\hline $\begin{array}{c}\text { Cardinality of } \\
\text { the Pareto fronts }\end{array}$ & 16 & 22 & 5 & 37 & 12 \\
\hline
\end{tabular}

Table 8 presents a comparison of the Pareto fronts obtained for the five scenarios when all the fronts are 
mixed in one new Pareto front. We can see that the adapted NSGA-III-90 completely dominates NSGA-III-0, NSGA-III-10, NSGA-III-50 and NSGA-III-100, which confirm that NSGA-III-90 is the best scenario.

Table 8: Comparisons of the performances of NSGA-III

\begin{tabular}{|c|c|c|c|c|c|c|}
\cline { 2 - 6 } \multicolumn{1}{c|}{} & $\begin{array}{c}\text { Total } \\
\text { of cardinality }\end{array}$ & $\begin{array}{c}\text { Scenario 1 } \\
\text { NSGA-III-0 }\end{array}$ & $\begin{array}{c}\text { Scenario 2 } \\
\text { NSGA-III-10 }\end{array}$ & $\begin{array}{c}\text { Scenario 3 } \\
\text { NSGA-III-50 }\end{array}$ & $\begin{array}{c}\text { Scenario 4 } \\
\text { NSGA-III-90 }\end{array}$ & $\begin{array}{c}\text { Scenario 5 } \\
\text { NSGA-III-100 }\end{array}$ \\
\hline $\begin{array}{c}\text { Cardinality of } \\
\text { the Pareto fronts }\end{array}$ & 37 & 0 & 0 & 0 & 37 & 0 \\
\hline
\end{tabular}

Based on the sensitivity analysis of the parameters of NSGA-III, we use the parameters that showed the best performance overall. Table 9 shows the different basic used parameters of respectively, WGA, RWGA, NSGA-II and NSGA-III.

Table 9: The based parameters settings

\begin{tabular}{|c|c|c|c|c|}
\hline Population size & Number of iterations & Pcrossover & Pmutation & Mutation Ratio \\
\hline 40 & 1000 & 0.1 & 0.9 & 0.3 \\
\hline
\end{tabular}

Table 10 presents the experimental results obtained using each approach (WGA, RWGA, NSGA-II and NSGA-III), where two performance indicators are used, the CPU calculation time (in seconds) and the cardinality of the Pareto fronts (number of optimal Pareto process plans) of each instance.

Table 10: CPU time and cardinality of the Pareto fronts of NSGA-II, NSGA-III, WGA and RWGA

\begin{tabular}{|c|c|c|c|c|c|c|c|c|}
\hline \multirow{2}{*}{ Instance } & \multicolumn{4}{|c|}{ CPU } & \multicolumn{3}{c|}{$\begin{array}{c}\text { Cardinality of the } \\
\text { Pareto fronts }\end{array}$} \\
\cline { 2 - 9 } & NSGA-II & NSGA-III & WGA & RWGA & NSGA-II & NSGA-III & WGA & RWGA \\
\hline $11-6$ & 909,56 & $\mathbf{5 8 6 . 3 9}$ & 1098.13 & 46844.85 & 23 & 13 & 8 & 9 \\
$12-6$ & 1031.09 & $\mathbf{6 5 6 . 3 4}$ & 1136.08 & 46967.99 & 12 & 11 & 5 & 3 \\
$14-5$ & 1072.30 & $\mathbf{6 8 7 . 9 6}$ & 1194.46 & 46900.97 & 7 & 6 & 5 & 8 \\
$20-10$ & 1525.80 & $\mathbf{1 1 0 4 . 3 9}$ & 1580.56 & 47358.45 & 14 & 8 & 4 & 2 \\
$30-15$ & 2212.30 & $\mathbf{1 6 8 2 . 3 6}$ & 2094.64 & 48834.73 & 36 & 27 & 4 & 4 \\
$45-20$ & 3590.60 & $\mathbf{2 9 4 8 . 7 0}$ & 3287.12 & 49075.64 & 5 & 6 & 8 & 2 \\
$50-20$ & 3764.54 & 3544.74 & $\mathbf{3 4 5 4 . 4 9}$ & 49315.01 & 7 & 13 & 4 & 3 \\
$100-20$ & 8371.45 & 8198.70 & $\mathbf{7 1 9 5 . 3 7}$ & 53269.42 & 11 & 13 & 8 & 2 \\
$100-20 \mathrm{bis}$ & 33022.97 & 31921.36 & $\mathbf{2 6 7 4 0 . 7 2}$ & 217941.44 & 21 & 37 & 5 & 2 \\
\hline
\end{tabular}

Table 11 presents a comparison of the Pareto fronts obtained by NSGA-III, WGA and RWGA, when the 
three fronts are mixed in one new Pareto front, where:

- Total cardinality: it corresponds to the size of the new Pareto front (ie. number of Pareto optimal process plans).

- \# Pareto front of WGA: it presents the number of Pareto optimal process plans obtained from WGA which are maintained in the new Pareto front (ie., contribution of WGA Pareto front in the new mixed Pareto front).

- \# Pareto front of RWGA: it presents the number of Pareto optimal process plans obtained from WGA which are maintained in the new Pareto front (ie., contribution of RWGA Pareto front in the new mixed Pareto front).

- \# Pareto front of NSGA-III: it presents the number of Pareto optimal process plans obtained from NSGA-III which are maintained in the new Pareto front (ie., contribution of NSGA-III Pareto front in the new mixed Pareto front).

Table 11: Comparisons of the performances of NSGA-III, WGA and RWGA

\begin{tabular}{|c|c|c|c|c|}
\hline \multirow{2}{*}{ Instance } & \multicolumn{4}{|c|}{$\begin{array}{l}\text { Combined Pareto fronts of } \\
\text { NSGA-III, WGA and RWGA }\end{array}$} \\
\hline & $\begin{array}{l}\text { Total } \\
\text { cardinality }\end{array}$ & $\begin{array}{c}\text { \# Pareto } \\
\text { front of } \\
\text { NSGA-III }\end{array}$ & $\begin{array}{l}\text { \# Pareto } \\
\text { front of } \\
\text { WGA }\end{array}$ & $\begin{array}{l}\text { \# Pareto } \\
\text { front of } \\
\text { RWGA }\end{array}$ \\
\hline $11-6$ & 15 & 12 & 2 & 1 \\
\hline $12-6$ & 11 & 11 & 0 & 0 \\
\hline $14-5$ & 6 & 6 & 0 & 0 \\
\hline $20-10$ & 8 & 8 & 0 & 0 \\
\hline $30-15$ & 27 & 27 & 0 & 0 \\
\hline $45-20$ & 6 & 6 & 0 & 0 \\
\hline $50-20$ & 13 & 13 & 0 & 0 \\
\hline $100-20$ & 13 & 13 & 0 & 0 \\
\hline 100-20bis & 37 & 37 & 0 & 0 \\
\hline
\end{tabular}

Table 12 and Table 13 show the hypervolume metric and spacing metric values associated to the obtained Pareto fronts for different instances using respectively NSGA-II, NSGA-III, WGA and RWGA. 
Table 12: Hypervolume of NSGA-II, NSGA-III, WGA and RWGA

\begin{tabular}{|c|c|c|c|c|}
\hline \multirow{2}{*}{ Instance } & \multicolumn{4}{|c|}{ Hypervolume } \\
\cline { 2 - 5 } & NSGA-II & NSGA-III & WGA & RWGA \\
\hline $11-6$ & $\mathbf{7 . 1 2 e + 1 0 2}$ & $1.20 \mathrm{e}+58$ & $7.91 \mathrm{e}+35$ & $3.39 \mathrm{e}+40$ \\
$12-6$ & $\mathbf{2 . 6 2 e}+\mathbf{5 3}$ & $9.45 \mathrm{e}+48$ & $3.42 \mathrm{e}+22$ & $3.12 \mathrm{e}+13$ \\
$14-5$ & $\mathbf{6 . 3 8 e + 3 1}$ & $1.8557 \mathrm{e}+27$ & $1.15 \mathrm{e}+23$ & $4.9316 \mathrm{e}+26$ \\
$20-10$ & $\mathbf{6 . 4 3 e}+\mathbf{6 5}$ & $4.04 \mathrm{e}+37$ & $1.33 \mathrm{e}+19$ & $3.64 \mathrm{e}+9$ \\
$30-15$ & $\mathbf{1 . 1 4 e}+\mathbf{1 7 3}$ & $5.32 \mathrm{e}+129$ & $4.73 \mathrm{e}+19$ & $4.28 \mathrm{e}+19$ \\
$45-20$ & $1.04 \mathrm{e}+25$ & $\mathbf{6 . 4 4 e}+\mathbf{3 0}$ & $3.89 \mathrm{e}+29$ & $1.40 \mathrm{e}+10$ \\
$50-20$ & $5.94 \mathrm{e}+35$ & $\mathbf{1 . 9 5 e}+\mathbf{6 6}$ & $3.72 \mathrm{e}+20$ & $2.66 \mathrm{e}+15$ \\
$100-20$ & $6.87 \mathrm{e}+59$ & $\mathbf{5 . 0 6 e}+\mathbf{7 0}$ & $7.40 \mathrm{e}+43$ & $8.4799 \mathrm{e}+10$ \\
$100-20 \mathrm{bis}$ & $6.69 \mathrm{e}+113$ & $\mathbf{2 . 3 1 e}+\mathbf{2 0 0}$ & $2.26 \mathrm{e}+27$ & $8.634 \mathrm{e}+10$ \\
\hline
\end{tabular}

Table 13: Spacing metric of NSGA-II, NSGA-III, WGA and RWGA

\begin{tabular}{|c|c|c|c|c|}
\hline \multirow{2}{*}{ Instance } & \multicolumn{4}{|c|}{ Spacing metric } \\
\cline { 2 - 5 } & NSGA-II & NSGA-III & WGA & RWGA \\
\hline $11-6$ & $\mathbf{2 1 5 . 8 7}$ & 220.45 & 879.81 & 304.90 \\
$12-6$ & 143.71 & $\mathbf{1 3 8 . 5 4}$ & 809.25 & 1863.37 \\
$14-5$ & 1050.6 & $\mathbf{1 1 8 . 7 7}$ & 323.64 & 432.68 \\
$20-10$ & 575.83 & $\mathbf{3 9 0 . 5 5}$ & 1130.3 & - \\
$30-15$ & 388.65 & $\mathbf{2 9 6 . 4 7}$ & 753.29 & 277.70 \\
$45-20$ & 1420 & $\mathbf{4 1 7 . 3 6}$ & 2412.7 & - \\
$50-20$ & 1150 & $\mathbf{3 2 1 . 5 7}$ & 2129.98 & 2771.9 \\
$100-20$ & 5630 & $\mathbf{5 9 4 1 . 8}$ & 6775.1 & - \\
$100-20 \mathrm{bis}$ & 188.5 & $\mathbf{1 8 5 . 2 4}$ & 688.79 & - \\
\hline
\end{tabular}

Note: For instances 20-10, 45-20, 100-20 and 100-20bis, when using RWGA, we have two optimal process plans where the spacing metric value automatically equals zero since the computed distance is equal to zero.

Four main observations can be taken from the results of the previous tables:

- Observations 1: From Table 10, RWGA has a time inconvenient in solving the problem. For the largest instance, WGA has shown better time consuming, but NSGA-III has acquired more Pareto fronts. From the other side, for smaller instances, NSGA-III takes less time including that the most powerful is NSGA-II for the cardinality. 
- Observations 2: From Table 11, we observe that NSGA-III dominates completely the other approaches.

- Observations 3: While the number of iterations increases (the last lines of Table 11 and Table 10, instance 100-20bis), NSGA-III outperforms NSGA-II, WGA and RWGA. It shows that NSGA-III enrichs the Pareto fronts and gives decision makers more variety of process plans to select.

- Observations 4: From Table 12 and Table 13, the results confirm that NSGA-III performs better and indicates a major progression of the region covered by the solutions of the Pareto front.

It is clear that, making a specific decision based on the results obtained without using TOPSIS technique is very difficult, while ensuring the best compromise between four objectives: total production cost, total production time, amount of hazardous liquid waste and amount of greenhouse gases emitted. To be able to apply TOPSIS, for each objective, it is important to define a weight so that TOPSIS can rank the different Pareto optimal process plans. In our case, the weights are respectively $0.15,0.15,0.35$ and 0.35 . Table 14 illustrates the ranking of the Pareto optimal process plans obtained using NSGA-III in case the of 100 operations and 20 reconfigurable machines when the number of iterations attempts 1000 . We have a total of 13 Pareto optimal process plans as shown in Figure 4.

Table 14: Pareto optimal process plans ranking using TOPSIS

\begin{tabular}{|c|c|c|c|c|c|}
\hline \multirow{2}{*}{ Process Plan } & \multirow{2}{*}{ Rank } & \multicolumn{4}{|c|}{$\begin{array}{l}\text { Pareto Optimal fronts } \\
\text { ranking using TOPSIS }\end{array}$} \\
\hline & & $f_{c}(€)$ & $f_{t}(\min )$ & $f_{L H W}(\mathrm{H} . \mathrm{u})$ & $f_{G H G}(\mathrm{~g})$ \\
\hline $\mathbf{P P}_{13}$ & 1 & 21494 & 1782 & 269943 & 20738 \\
\hline $\mathrm{PP}_{4}$ & 2 & 21677 & 1777 & 270346 & 20722 \\
\hline $\mathrm{PP}_{8}$ & 3 & 22087 & 1736 & 273860 & 20440 \\
\hline $\mathrm{PP}_{11}$ & 4 & 21889 & 1762 & 272162 & 20725 \\
\hline $\mathrm{PP}_{9}$ & 5 & 21881 & 1732 & 275843 & 20675 \\
\hline $\mathrm{PP}_{5}$ & 6 & 21129 & 1733 & 276054 & 20913 \\
\hline $\mathrm{PP}_{6}$ & 7 & 21617 & 1781 & 274429 & 20969 \\
\hline $\mathrm{PP}_{7}$ & 8 & 21768 & 1762 & 276762 & 20862 \\
\hline $\mathrm{PP}_{3}$ & 9 & 21601 & 1773 & 275484 & 21013 \\
\hline $\mathrm{PP}_{2}$ & 10 & 21400 & 1810 & 273813 & 21092 \\
\hline $\mathrm{PP}_{10}$ & 11 & 21490 & 1796 & 275723 & 20987 \\
\hline $\mathrm{PP}_{12}$ & 12 & 21010 & 1710 & 279729 & 20861 \\
\hline $\mathrm{PP}_{1}$ & 13 & 22031 & 1709 & 300441 & 21489 \\
\hline
\end{tabular}




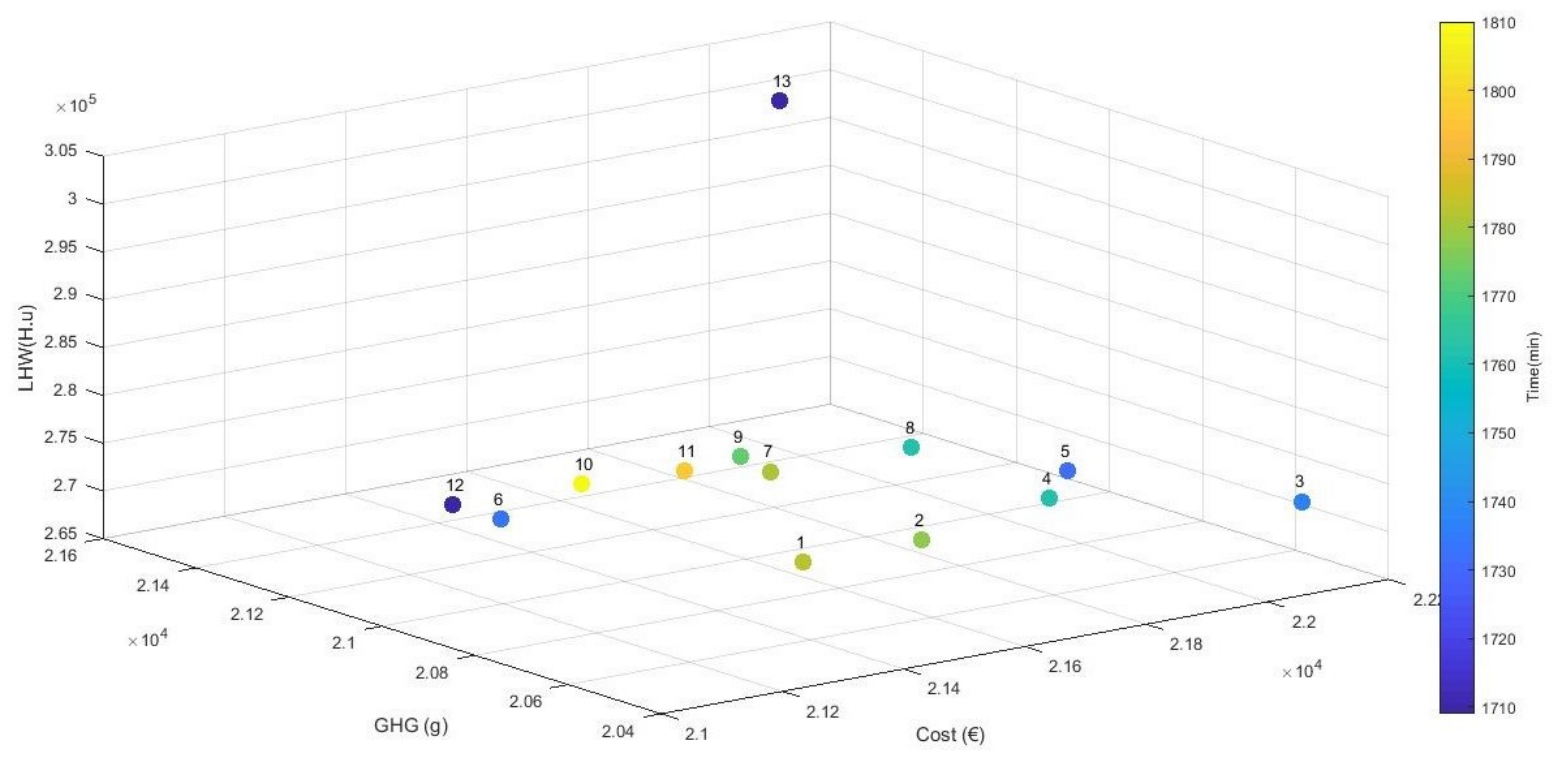

Figure 4: Graphical representation of the Pareto optimal fronts using NSGA-III

- Observation 5: From Table 14, based on the weights associated to the four objectives, we can see that, TOPSIS ranks: (i) $P P_{13}$ first with a total production cost equals to 21494 (€), a total production time equals 1782 (minutes), a total amount of hazardous waste equals 269943 (Hazardous unit) and a total amount of emitted greenhouse gases equals to 20738 (g) and (ii) $P P_{1}$ last with a total production cost equals to 22031 (€), a total production time equals 1709 (minutes), a total amount of hazardous waste equals 300441 (Hazardous unit) and a total amount of emitted greenhouse gases equals to 21489 (g). We can see that, hazardous waste and emitted greenhouse gases are predominant in ranking the Pareto optimal process plans.

\section{Conclusions}

In this paper, we considered an environmental oriented multi-objective reconfigurable manufacturing system design (ie., sustainable reconfigurable machines and tools selection) in the case of a single unit process plan generation. First, a non-linear multi-objective integer program (NL-MOIP) was presented, where four objectives are minimised respectively, the total production cost, the total production time, the amount of the greenhouse gases and the hazardous liquid wastes emitted by the machines. Second, to tackle the problem, we adapted four evolutionary approaches, respectively, WGA, RWGA, NSGA-II and NSGA-III. To show the efficiency of the four approaches, several instances of the problem were experimented and the obtained results were analysed using three metrics respectively hypervolume, spacing metric and cardinality of the mixed Pareto fronts. Furthermore, the influences of the probabilities of genetic operators on the convergence 
of the adapted NSGA-III were evaluated and TOPSIS method was used to help the decision maker ranking and selecting the best process plans.

For future works, in addition to reducing the traditional total production cost and completion time, minimizing the maximum machines exploitation time can be considered as a novel optimization criterion for high-quality products. Other evolutionary-based approaches such as AMOSA, MOPSO, etc., can be adapted and compared. Moreover, we intend to extend the work to address the multi-unit process plan generation problem. Finally, the integration of process plan generation and scheduling problems in sustainable reconfigurable manufacturing environment (S-IPPS: sustainable integrated process planning and scheduling) for multiple contexts such as: dynamic, stochastic and smart, will be challenging and of great interests.

- Ethical Approval: The submitted work is original and has never been published elsewhere in any form or language.

- Consent to Participate: 'Not applicable'

- Consent to Publish: 'Not applicable'

- Authors Contributions: All the authors have involved equally in the realized work.

1. Miss Khettabi: Paper writing, problem formulation, approaches proposal and experimental performing and analysis

2. Prof. Benyoucef: Paper writing, problem formulation, approaches proposal and experimental performing and analysis

3. Prof. Boutiche: Paper writing, problem formulation, approaches proposal and experimental performing and analysis.

- Funding: 'Not applicable'

- Competing Interests: 'Not applicable'

- Availability of data and materials: The used data and materials are available when requested.

\section{References}

Afrin, K., Iquebal, A. S., Kumar, S. K., Tiwari, M., Benyoucef, L., \& Dolgui, A. (2016). Towards green automated production line with rotary transfer and turrets: a multi-objective approach using a binary scatter tabu search procedure. International Journal of Computer Integrated Manufacturing, 29, 768-785.

Allwood, J., Laursen, S. E., Russell, S., de Rodriguez, C. M., \& Bocken, N. (2008). An approach to scenario analysis of the sustainability of an industrial sector applied to clothing and textiles in the uk. Journal of Cleaner production, 16, 1234-1246. 
Battaïa, O., Benyoucef, L., Delorme, X., Dolgui, A., \& Thevenin, S. (2020). Sustainable and energy efficient reconfigurable manufacturing systems. In Reconfigurable Manufacturing Systems: From Design to Implementation (pp. 179-191). Springer.

Bensmaine, A., Dahane, M., \& Benyoucef, L. (2013). A non-dominated sorting genetic algorithm based approach for optimal machines selection in reconfigurable manufacturing environment. Computers $\&$ Industrial Engineering, 66, 519-524.

Bi, Z. (2011). Revisiting system paradigms from the viewpoint of manufacturing sustainability. Sustainability, 3, 1323-1340.

Chaube, A., Benyoucef, L., \& Tiwari, M. K. (2012). An adapted nsga-2 algorithm based dynamic process plan generation for a reconfigurable manufacturing system. Journal of Intelligent Manufacturing, 23, $1141-1155$.

Choi, Y.-C., \& Xirouchakis, P. (2015). A holistic production planning approach in a reconfigurable manufacturing system with energy consumption and environmental effects. International Journal of Computer Integrated Manufacturing, 28, 379-394.

Deb, K., \& Jain, H. (2014). An evolutionary many-objective optimization algorithm using reference-pointbased nondominated sorting approach, part i: solving problems with box constraints. IEEE transactions on evolutionary computation, 18, 577-601.

Deb, K., Pratap, A., Agarwal, S., \& Meyarivan, T. (2002). A fast and elitist multiobjective genetic algorithm: Nsga-ii. IEEE transactions on evolutionary computation, 6, 182-197.

ElMaraghy, H. A. (2007). Reconfigurable process plans for responsive manufacturing systems. In Digital enterprise technology (pp. 35-44). Springer.

Fang, K., Uhan, N., Zhao, F., \& Sutherland, J. W. (2011). A new shop scheduling approach in support of sustainable manufacturing. In Glocalized solutions for sustainability in manufacturing (pp. 305-310). Springer.

Goyal, K. K., Jain, P., \& Jain, M. (2012). Optimal configuration selection for reconfigurable manufacturing system using nsga ii and topsis. International Journal of Production Research, 50, 4175-4191.

Haddou-Benderbal, H., \& Benyoucef, L. (2019). Machine layout design problem under product family evolution in reconfigurable manufacturing environment: a two-phase-based amosa approach. The International Journal of Advanced Manufacturing Technology, 104, 375-389.

Haddou-Benderbal, H., Dahane, M., \& Benyoucef, L. (2016). Hybrid heuristic to minimize machine's unavailability impact on reconfigurable manufacturing system using reconfigurable process plan. IFACPapersOnLine, 49, 1626-1631. 
Haddou-Benderbal, H., Dahane, M., \& Benyoucef, L. (2018). Modularity assessment in reconfigurable manufacturing system (rms) design: an archived multi-objective simulated annealing-based approach. The International Journal of Advanced Manufacturing Technology, 94, 729-749.

Hasan, F., \& Jain, P. (2015). Genetic modelling for selecting optimal machine configurations in reconfigurable manufacturing system. In Applied Mechanics and Materials (pp. 1229-1239). Trans Tech Publ volume 789.

Howard, M. (2014). Sustainable manufacturing initiative (smi): a true public-private dialogue. The US Department of Commerce, .

Huband, S., Hingston, P., While, L., \& Barone, L. (2003). An evolution strategy with probabilistic mutation for multi-objective optimisation. In The 2003 Congress on Evolutionary Computation, 2003. CEC'03. (pp. 2284-2291). IEEE volume 4.

Hwang, C.-L., Lai, Y.-J., \& Liu, T.-Y. (1993). A new approach for multiple objective decision making. Computers \& operations research, 20, 889-899.

Jawahir, I., Badurdeen, F., Goldsby, T., \& Iyengar, D. (2009). Assessment of product and process sustainability: towards developing metrics for sustainable manufacturing. In NIST workshop on sustainable manufacturing (pp. 13-15).

Jayal, A., Badurdeen, F., Dillon Jr, O., \& Jawahir, I. (2010). Sustainable manufacturing: Modeling and optimization challenges at the product, process and system levels. CIRP Journal of Manufacturing Science and Technology, 2, 144-152.

Koffi, B., Cerutti, A. K., Duerr, M., Iancu, A., Kona, A., \& Janssens-Maenhout, G. (2017). Covenant of mayors for climate and energy: Default emission factors for local emission inventories. Joint Research Centre $(J R C)$, .

Konak, A., Coit, D. W., \& Smith, A. E. (2006). Multi-objective optimization using genetic algorithms: A tutorial. Reliability engineering \& system safety, 91, 992-1007.

Koren, Y. (2006). General rms characteristics. comparison with dedicated and flexible systems. In Reconfigurable manufacturing systems and transformable factories (pp. 27-45). Springer.

Koren, Y. (2010). The global manufacturing revolution: product-process-business integration and reconfigurable systems volume 80. John Wiley \& Sons.

Koren, Y., Gu, X., \& Guo, W. (2018). Reconfigurable manufacturing systems: Principles, design, and future trends. Frontiers of Mechanical Engineering, 13, 121-136.

Koren, Y., Heisel, U., Jovane, F., Moriwaki, T., Pritschow, G., Ulsoy, G., \& Van Brussel, H. (1999). Reconfigurable manufacturing systems. CIRP annals, 48, 527-540. 
Koren, Y., \& Shpitalni, M. (2010). Design of reconfigurable manufacturing systems. Journal of manufacturing systems, 29, 130-141.

Küster, T., Lützenberger, M., Freund, D., \& Albayrak, S. (2013). Distributed evolutionary optimisation for electricity price responsive manufacturing using multi-agent system technology. Int Journal On Advances in Intelligent Systems, 7.

Maganha, I., Silva, C., \& Ferreira, L. M. D. (2018). Understanding reconfigurability of manufacturing systems: An empirical analysis. Journal of Manufacturing Systems, 48, 120-130.

Massimi, E., Khezri, A., Haddou Benderbal, H., \& Benyoucef, L. (2020). A heuristic-based non-linear mixed integer approach for optimizing modularity and integrability in a sustainable reconfigurable manufacturing environment. The International Journal of Advanced Manufacturing Technology, 108, 1997-2020.

Mehrabi, M. G., Ulsoy, A. G., \& Koren, Y. (2000). Reconfigurable manufacturing systems: Key to future manufacturing. Journal of Intelligent manufacturing, 11, 403-419.

Moon, J.-Y., Shin, K., \& Park, J. (2013). Optimization of production scheduling with time-dependent and machine-dependent electricity cost for industrial energy efficiency. The International Journal of Advanced Manufacturing Technology, 68, 523-535.

Mouzon, G., Yildirim, M. B., \& Twomey, J. (2007). Operational methods for minimization of energy consumption of manufacturing equipment. International Journal of production research, 45, 4247-4271.

Murata, T., Ishibuchi, H., \& Tanaka, H. (1996). Multi-objective genetic algorithm and its applications to flowshop scheduling. Computers $\mathcal{E}$ industrial engineering, 30, 957-968.

Musharavati, F., \& Hamouda, A. (2012). Enhanced simulated-annealing-based algorithms and their applications to process planning in reconfigurable manufacturing systems. Advances in Engineering Software, $45,80-90$.

Nourelfath, M., Ait-Kadi, D., \& Soro, I. (2002). Optimal design of reconfigurable manufacturing systems. In IEEE international conference on systems, man and cybernetics (pp. 6-pp). IEEE volume 3.

Spicer, P., \& Carlo, H. J. (2007). Integrating reconfiguration cost into the design of multi-period scalable reconfigurable manufacturing systems, .

Srinivas, N., \& Deb, K. (1995). A fast and elitist multiobjective genetic algorithm: Nsga-ii. Evolutionary Computing, 2, 221-248.

Stoycheva, S., Marchese, D., Paul, C., Padoan, S., Juhmani, A.-s., \& Linkov, I. (2018). Multi-criteria decision analysis framework for sustainable manufacturing in automotive industry. Journal of Cleaner Production, $187,257-272$. 
Swamidass, P. M. (2000). Encyclopedia of production and manufacturing management. Springer Science \& Business Media.

Touzout, F. A., \& Benyoucef, L. (2018b). Sustainable multi-unit process plan generation in a reconfigurable manufacturing environment: A comparative study of three hybrid-meta-heuristics. In 2018 IEEE 23rd International Conference on Emerging Technologies and Factory Automation (ETFA) (pp. 661-668). IEEE volume 1.

Touzout, F. A., \& Benyoucef, L. (2019). Multi-objective multi-unit process plan generation in a reconfigurable manufacturing environment: a comparative study of three hybrid metaheuristics. International Journal of Production Research, 57, 7520-7535.

Wang, G. X., Huang, S. H., Yan, Y., \& Du, J. J. (2017). Reconfiguration schemes evaluation based on preference ranking of key characteristics of reconfigurable manufacturing systems. The International Journal of Advanced Manufacturing Technology, 89, 2231-2249.

Yusta, J., Torres, F., \& Khodr, H. (2010). Optimal methodology for a machining process scheduling in spot electricity markets. Energy Conversion and Management, 51, 2647-2654.

Zhu, Z., Chu, F., Dolgui, A., Chu, C., Zhou, W., \& Piramuthu, S. (2018). Recent advances and opportunities in sustainable food supply chain: a model-oriented review. International Journal of Production Research, $56,5700-5722$. 
Figures
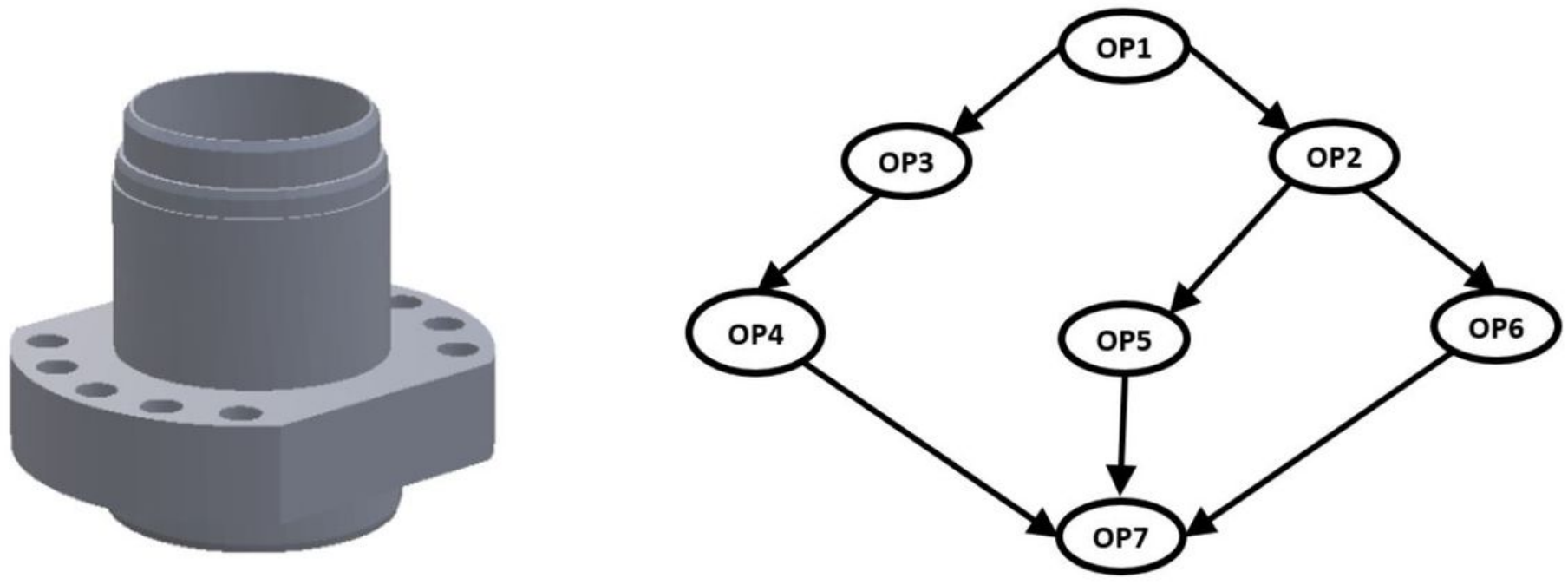

Figure 1

An illustrative product schema and operation precedence graph 


\begin{tabular}{|l|l|l|l|l|l|l|l|}
\hline \multirow{4}{*}{ Parent 1 } & 0.34 & 0.45 & 0.76 & 0.12 & 0.55 & 0.87 & 0.62 \\
\cline { 2 - 7 } & 0.48 & 0.87 & 0.11 & 0.56 & 0.63 & 0.28 & 0.05 \\
\hline
\end{tabular}

\begin{tabular}{|c|c|c|c|c|c|c|c|}
\hline \multirow{2}{*}{ arent 2} & 0.23 & 0.57 & 0.17 & 0.88 & 0.79 & 0.68 & 0.04 \\
\hline & 0.69 & 0.21 & 0.83 & 0.09 & 0.17 & 0.52 & 0.79 \\
\hline
\end{tabular}

\begin{tabular}{|l|l|l|l|l|l|l|l|}
\hline \multirow{4}{*}{ Child 1 } & 0.34 & 0.45 & 0.76 & 0.12 & 0.79 & 0.68 & 0.04 \\
\cline { 2 - 8 } & 0.48 & 0.87 & 0.11 & 0.56 & 0.17 & 0.52 & 0.79 \\
\hline
\end{tabular}

\begin{tabular}{|c|c|c|c|c|c|c|c|}
\hline \multirow{2}{*}{ Child 2} & 0.23 & 0.57 & 0.17 & 0.88 & 0.55 & 0.87 & 0.62 \\
\hline & 0.69 & 0.21 & 0.83 & 0.09 & 0.63 & 0.28 & 0.05 \\
\hline
\end{tabular}

Figure 2

Illustrative Crossover operations 


\begin{tabular}{|l|l|l|l|l|l|l|l|}
\hline \multirow{4}{*}{ Child 1 } & $\mathbf{0 . 3 4}$ & 0.45 & $\mathbf{0 . 7 6}$ & $\mathbf{0 . 1 2}$ & 0.55 & $\mathbf{0 . 8 7}$ & $\mathbf{0 . 6 2}$ \\
\cline { 2 - 7 } & $\mathbf{0 . 4 8}$ & 0.87 & $\mathbf{0 . 1 1}$ & $\mathbf{0 . 5 6}$ & 0.63 & $\mathbf{0 . 2 8}$ & $\mathbf{0 . 0 5}$ \\
\hline
\end{tabular}

\begin{tabular}{|l|l|l|l|l|l|l|}
\hline $\mathbf{0 . 3 4}$ & 0.55 & $\mathbf{0 . 7 6}$ & $\mathbf{0 . 1 2}$ & 0.45 & $\mathbf{0 . 8 7}$ & $\mathbf{0 . 6 2}$ \\
\hline $\mathbf{0 . 4 8}$ & 0.63 & $\mathbf{0 . 1 1}$ & $\mathbf{0 . 5 6}$ & 0.87 & $\mathbf{0 . 2 8}$ & $\mathbf{0 . 0 5}$ \\
\hline
\end{tabular}

Figure 3

Illustrative mutation operations

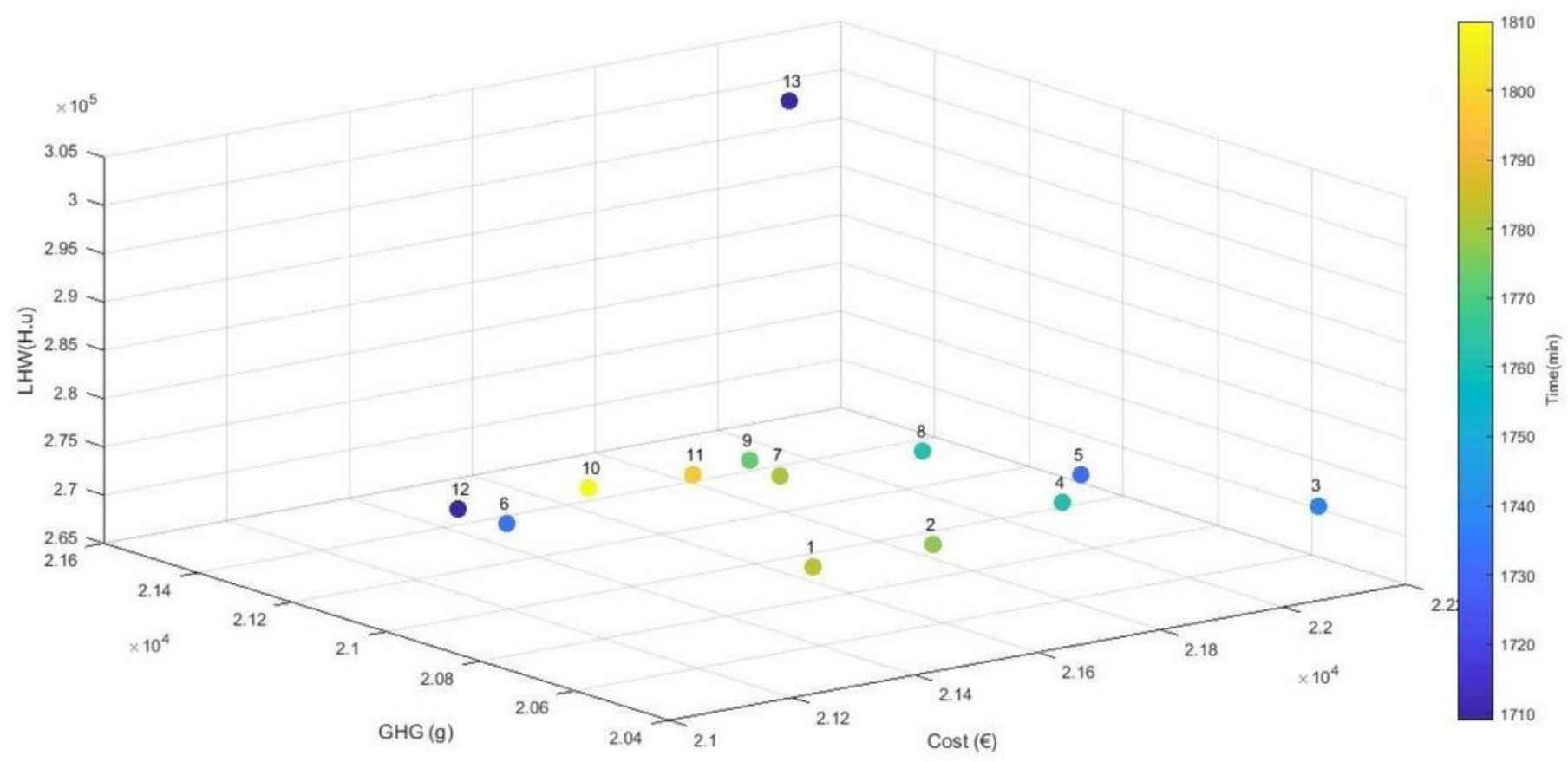

Figure 4

Graphical representation of the Pareto optimal fronts using NSGA-III 